\title{
Structure and stress field of the lithosphere between Pamir and Tarim
}

\author{
Wasja Bloch $^{1 *}$, Bernd Schurr ${ }^{1}$, Xiaohui Yuan ${ }^{1}$, Lothar Ratschbacher ${ }^{2}$, \\ Sanaa Reuter ${ }^{2}$, Sofia-Katerina Kufner ${ }^{1,3}$, Qiang $\mathbf{X u}^{4,5}$, Junmeng Zhao ${ }^{4,5}$ \\ ${ }^{1}$ GFZ German Research Centre for Geosciences, 14473 Potsdam, Germany \\ ${ }^{2}$ Geologie, Technische Universität Bergakademie Freiberg, 09599 Freiberg, Germany \\ ${ }^{3}$ British Antarctic Survey, Cambridge CB3 0ET, England \\ ${ }^{4}$ Key Laboratory of Continental Collision and Plateau Uplift, Institute of Tibetan Plateau Research, \\ Chinese Academy of Sciences, Beijing 100101, China \\ ${ }^{5}$ CAS Center for Excellence in Tibetan Plateau Earth Sciences, Beijing 100101, China
}

This manuscript is a non-peer reviewed preprint submitted to EarthArXiv. Submitted to Geophysical Research Letters (Wiley)

\section{Key Points:}

- New local earthquake catalog and seismic P-wave velocity model for the eastern Pamir

- Elevated velocities outline the northern and eastern margins of the Indian mantle indenter beneath the Pamir plateau

- Indenter overturns the eastern end of the Asian slab and terminates along a transform margin against the Tarim block

*Now at: Earth, Ocean and Atmospheric Sciences, University of British Columbia, Vancouver, Canada.

Corresponding author: Wasja Bloch, wbloch@eoas.ubc.ca 


\begin{abstract}
The Pamir plateau protrudes $\sim 300 \mathrm{~km}$ between the Tajik- and Tarim-basin lithosphere of Central Asia. Whether its salient location and shape are caused by forceful indentation of a promontory of Indian mantle lithosphere is debated. We present a new localseismicity and focal-mechanism catalog, and a $\mathrm{P}$-wave velocity model of the eastern part of the collision system. The data suggest a south-dipping Asian slab that overturns in its easternmost segment. The largest principal stress at depth acts normal on the slab and is orientated parallel to the plate convergence direction. In front (south) of the Asian slab, a volume of mantle with elevated velocities and lined by weak seismicity constitutes the postulated Indian mantle indenter. We propose that the indenter delaminates and overturns the Asian slab, underthrusts the Tarim lithosphere along a compressive transform boundary, and controls the location and shape of the Pamir plateau.
\end{abstract}

\title{
Plain Language Summary
}

The Pamir plateau stands out between the Tajik basin to the west and the Tarim basin to the east. Its location and shape are either caused by a part of the Indian continent that protrudes below Pamir's crust, or thinned lithosphere of a former Asian basin existed in the place of the Pamir and subducted during the collision of India with Asia. Our new seismological data show that the Asian slab - a displaced part or slice of the Tarim-Tajik-basin lithosphere - is overturned beneath the eastern Pamir. A zone of high seismic velocities, indicative of a relatively cold and rigid mantle lithosphere, occurs in front (south) of the Asian slab. A seismically active zone with low seismic velocities is squeezed between this structure and the Tarim lithosphere. Together, these observations trace the northern and eastern margin of the Indian mantle indenter that predefines the shape of the Pamir plateau.

\section{Introduction}

The salient Pamir plateau is part of the India-Asia collision system. It is offset by $\sim 300 \mathrm{~km}$ to the north in relation to the adjacent Tibet plateau and protrudes between the Tajik basin in the west and the cratonic block of the Tarim basin in the east (e.g. $\mathrm{Lu}$ et al., 2008). The northern Pamir and the Kunlun of northwestern Tibet comprise subduction-accretion-arc complexes accreted to and built on Asian continental basement. The central and southern Pamir and the Karakorum and Hindu-Kush represent Gondwanaderived microcontinents and subduction-accretion-arc complexes (Fig. 1; Burtman \& Molnar, 1993; Schwab et al., 2004).

Beneath the Pamir, a band of intermediate-depth $(50-250 \mathrm{~km})$ earthquakes, extending from the southwestern Pamir northeastward into the central Pamir, bends eastward, and shows diminished earthquake activity beneath the eastern Pamir (Fig. 2; Pegler \& Das, 1998; Sippl, Schurr, Yuan, et al., 2013). Receiver function images (Schneider et al., 2013) and the analysis of guided waves (Mechie et al., 2019) show that the earthquakes in the western and central Pamir reside in a 10-15 km thick, E- to S-dipping low velocity zone (LVZ) connected to the Asian lithosphere; seismic velocities indicate that the LVZ represents continental crust, which has - together with the underlying mantle lithospherebeen interpreted as the Asian slab (Schneider et al., 2013; Sippl, Schurr, Tympel, et al., 2013; Mechie et al., 2019). Beneath the northwestern Kunlun, diffuse seismicity at 100-150 km depth was attributed to Tarim lithosphere underthrusting the Pamir (Fan et al., 1994; Pegler \& Das, 1998).

To understand the oroclinal shape of the Pamir, the intermediate-depth seismicity beneath the Hindu-Kush, Pamir and Kunlun, and the along-strike changes of the deep structure from the Hindu-Kush through the Pamir to Tibet and the Himalaya, it is a key to know whether Asian lithosphere subducts as a narrow, back-rolling slab of thinned 
crust (Burtman \& Molnar, 1993; Sobel et al., 2013) or if Asian lower crust and mantle lithosphere is forced to subduct/delaminate due to indentation by cratonic Indian mantle lithosphere (Kufner et al., 2016; Metzger et al., 2017). If an indenter governs the shape of the Pamir plateau, its properties can best be characterized at its margins, where it interacts with and has a detectable contrast to the bounding units. For the western margin, Kufner, Schurr, et al. (2018) argued that a sinistral-oblique transform margin separates indenting cratonic Indian mantle lithosphere beneath the Pamir from subducting Indian continental-margin lithosphere below the Hindu-Kush. The subduction model postulates rollback of a narrow Asian slab of thinned continental crust that involves mantle corner flow and a subduction-transform edge propagator fault, separating the subducting Asian slab and its hanging wall from the Tarim block to the east. Geophysical data indicate that the hinterland crust is not thinned (>50 km; Schneider et al., 2019), questioning the premise of the rollback model, because thick buoyant continental crust typically does not subduct beneath a continent as a whole (e.g Z.-H. Li et al., 2016; Kelly $\&$ Beaumont, 2021). The indentation model involves forced Asian slab subduction and delamination due to flat-slab underthrusting of a mechanically-strong Indian continental lithospheric mantle indenter, a process recently modeled for the Pamir (Kelly \& Beaumont, 2021). The indenter is imaged by refraction seismology and local body wave tomography as a high velocity zone (HVZ) south of the Asian slab (Mechie et al., 2012; Sippl, Schurr, Tympel, et al., 2013). Teleseismic body and surface wave tomography shows that it connects with the exposed Indian craton (e.g. C. Li et al., 2008; Agius \& Lebedev, 2013; van Hinsbergen et al., 2019; Liang et al., 2020); its northern extent remained unresolved due to the smearing of the indenter HVZ with the HVZ that represents cratonic Asia.

Herein, intermediate-depth earthquakes, focal-mechanism based stress data, and a P-wave velocity $\left(V_{P}\right)$ model derived from new and published local seismological data in companionship with new receiver functions (Xu et al., 2021) illuminate the lithospheric configuration of the central and eastern Pamir and the boundary zone with the Tarim craton. Our data characterize the northern tip of an indenter -interpreted as a promontory of Indian mantle lithosphere - and its eastern edge, where it underthrusts on the lithosphere of the Tarim block.

\section{Data and Methods}

We used seismograms recorded with two new local seismic networks that were in operation between August 2015 and July 2017 in the eastern Pamir, northwestern Kunlun, and northwestern Tarim basin (Text S1; Yuan, Schurr, Bloch, et al., 2018; Yuan, Schurr, Kufner, \& Bloch, 2018) and additional regional stations (PMP International (Tajikistan), 2005; SEISDMC, 2021). We detected seismic events using a waveform-envelopecoherence-based approach (Comino et al., 2017) and picked P- and S-wave arrival times using calibrated automatic picking algorithms (Text S2; Aldersons, 2004; Diehl et al., 2009).

Using additional data of an existing earthquake catalog from the western and central Pamir (Sippl, Schurr, Tympel, et al., 2013), we inverted for the 3-D subsurface $V_{P}$ structure (Thurber, 1983). We masked out poorly resolved volumes of the tomogram based on a checkerboard resolution test and performed synthetic recovery tests for the anomalies that are most important to our interpretation (Text S3; Fig. S1-S11).

We jointly located the newly and previously (Sippl, Schurr, Tympel, et al., 2013) detected seismicity at intermediate depth in the 3-D $V_{P}$ model, assessed location uncertainties (Lomax et al., 2000) and performed a relative event relocation for events that were $<10 \mathrm{~km}$ apart (Waldhauser \& Ellsworth, 2000) (Text S4; Fig. S12-S15), yielding a unified catalog of 1,493 events at intermediate depth. 
We determined focal mechanisms of the strongest of the newly located events and inverted for the deviatoric unit stress tensor from which we report the orientation of the three principal axes $\left(\sigma_{1}>\sigma_{2}>\sigma_{3}\right)$, orientation uncertainties, and relative stress magnitudes (Text S5; Fig. S16). The seismicity catalog (Data Set S1), focal mechanism catalog (Data Set S2), and the $V_{P}$ structure (Data Set S3) are published in the Supplemental Material.

\section{Seismicity}

Crustal seismicity of the upper $30 \mathrm{~km}$ is dominated by the aftershock sequences of strong earthquakes that struck the Pamir in 2015/16 and is omitted from the main figures. The middle and lower crust (30-50 km depth) is essentially aseismic (Fig. S2). Intermediatedepth earthquakes in the central and eastern Pamir could be localized with a median $(5 \%$ $95 \%$ quantile) uncertainty of $2.3(1.1-6.4) \mathrm{km}$ in longitudinal direction, $2.0(1.0-5.0) \mathrm{km}$ in latitude and $3.2(1.8-9.4) \mathrm{km}$ in depth (Fig. S15). They outline three steeply-dipping, planar to curviplanar segments separated by regions of sparse seismicity (Fig. 2; Fig. 3).

Segment 1 begins at $72.8^{\circ} \mathrm{E}, 38^{\circ} \mathrm{N}$, in continuation of the NE-striking, planar, seismically active structure farther to the southwest (Fig. 2; Schneider et al., 2013; Sippl, Schurr, Yuan, et al., 2013). It forms an S- to SE-dipping band between $73.0^{\circ} \mathrm{E}$ and $74.3^{\circ} \mathrm{E}$, and shows vigorous seismicity between $70-180 \mathrm{~km}$ depth in its easternmost part (Fig. 3A; Fig. S12); farther east, seismic activity decreases.

Segment 2 in the eastern Pamir - in the direct continuation of segment 1 - contains a few earthquakes at 50-80 km depth in a S-dipping structure. Below, at 80-170 km depth, the earthquake-defined band dips N (Fig. 2, dotted lines in Fig. 3B; Fig. S14g-i). Seismicity in segment 2 is less intense compared to segment 1 (Fig. S12).

Seismicity in segment 3 forms a continuous, NNW-striking structure at $80-120 \mathrm{~km}$ depth between $37^{\circ} \mathrm{N}$ and $38^{\circ} \mathrm{N}$; it follows the northwestern Kunlun (Fig. 2; Fig. 3C). Seismic activity is comparably weak (Fig. S12).

In all segments, focal mechanisms show dominantly thrust and subordinately strikeslip faulting. Accordingly, the regional stress tensor at intermediate depth indicates a thrust regime with a near-horizontal $\sigma_{1}$, trending $\mathrm{N} 13^{\circ} \mathrm{W} \pm 60^{\circ}$ (95\% confidence interval) and near vertical $\sigma_{3}$ (Fig. 2). Inverting for the stress of the three segments separately yields similar directions, despite strongly variable uncertainties due to the disparate amounts of data (Fig. S16). The azimuth of $\sigma_{1}$ is about parallel to the azimuth of the GNSS vectors in the southern and central Pamir (south of $38.8^{\circ} \mathrm{N}$ ), $\mathrm{N} 12^{\circ} \mathrm{W} \pm 4^{\circ}$ (Fig. 2; Ischuk et al., 2013; Zubovich et al., 2010).

\section{Velocity Structure}

In the shallow crust, the sedimentary rock section of the Tarim basin is characterized by $V_{P}<5 \mathrm{~km} / \mathrm{s}$ ( TL in Fig. 3B-D). In the middle-lower crust, the Tarim basement appears discontinuously with $V_{P}=6.5-7.5 \mathrm{~km} / \mathrm{s}$ ( $T H$ in Fig. $3 \mathrm{C}$ and $3 \mathrm{E}$ ) close to the poor-resolution rim of the tomographic volume. A LVZ is located in the mantle of northwestern Tarim ( $A L$ in Fig. $3 \mathrm{G}$ ). An arcuate crustal LVZ with $V_{P}=5-6, \mathrm{~km} / \mathrm{s}$ - lower than the overburden and the background velocity at this depth (Fig. S1a) - extends below the northern Pamir, the Kongur Extensional System, and the northwestern Kunlun ( $P L$ in Figs. $3 \mathrm{~A}-\mathrm{C}$ and $3 \mathrm{E}$ ). It is sandwiched between the Tarim basement $T H$ and a zone of higher $V_{P}=6-7 \mathrm{~km} / \mathrm{s}$ in the central Pamir ( $P H$ in Fig. 3A; Fig. 3E). Recovery tests indicate that $P H$ and $P L$ can be resolved under the given ray geometry and are not smearing artifacts form the anomalies below (Fig. S10a and b).

A good agreement with the receiver function Moho can be accomplished when defining the tomographic Moho at $V_{P}=8 \mathrm{~km} / \mathrm{s}$. At mantle depths $(>70 \mathrm{~km})$, dipping LVZs 
with respect to the background model are located above the seismicity in segments 1-3 (7-8 km/s, L1, L2, L3 in Fig. 3A-C and 3F). The LVZs L2 and L3 of segments 2 and 3 appear continuous in map view (Fig. $3 \mathrm{~F}$ ), but are separated by the seismicity of segment 2 (Fig. 3B). The seismically active structures are underlain by HVZs $(8.5-9.5 \mathrm{~km} / \mathrm{s}, H 1$, H2, H3 in Fig. 3A-C and 3G) and have the same dip as the LVZs above. The contrast between the LVZs and the underlying HVZs is well resolved (Fig. S10a, b, d). The location and dip of $L 2$ and $L 3$ coincide with Moho troughs identified in receiver functions (Fig. S17; Xu et al., 2021), substantiating our observations. The HVZs are resolved to a depth of $105-120 \mathrm{~km}$ (Fig. S10b and d). H1 and H2 are continuous along strike below $\sim 105 \mathrm{~km}$ depth (Fig. 3G). H2 and H3 touch, but are separated by seismicity in the same way as L2 and L3 (Fig. 3B and 3G). L1 and H1 as well as L3 and H3 dip in the same direction as the seismicity (Fig. $3 \mathrm{~A}$ and $3 \mathrm{C}$ ).

\section{Interpretation and Discussion}

We visualize our interpretation of the lithospheric architecture of the central and eastern Pamir in the block diagram of Figure 4. The occurrence of earthquakes at intermediate depth requires a process that facilitates seismic failure despite high temperatures, because ductile deformation dominates below 20-30 km depth for quartz- and feldspar-, and below $50 \mathrm{~km}$ for olivine-dominated lithologies (Brace \& Kohlstedt, 1980; Tullis \& Yund, 1992). Eclogite-facies metamorphism has been found to excite intermediate-depth seismicity in oceanic subduction regimes (Incel et al., 2017; Kita et al., 2006; Yuan et al., 2000), as well as in continental lower crustal rocks (Incel et al., 2019; Jamtveit et al., 2018; John et al., 2009). Receiver function images show that upon eclogitization (in the broadest sense), the crust may become indistinguishable from the surrounding mantle in terms of seismic velocities (Rondenay et al., 2008); it may therefore yield the pattern of a LVZ shaping a local Moho trough that disappears at larger depths where the seismicity that we observe in the three segments starts. It may additionally cause densification of the slab that would promote subduction under its own weight (Ringwood \& Green, 1966). The imaged velocities of $L 1, L 2$ and $L 3(7-8 \mathrm{~km} / \mathrm{s})$ that are too high for non-eclogized crust may either indicate already partial eclogitization at the onset of subduction, or result from smearing of a possibly only $10-15 \mathrm{~km}$ thick anomaly onto the arbitrarily but generally wider positioned inversion nodes (Sippl, Schurr, Tympel, et al., 2013); the large thickness of $L 1$ may result from additional pooling of more buoyant middle crust on top of the down-going plate (Sippl, Schurr, Tympel, et al., 2013). Correspondingly, Sippl, Schurr, Tympel, et al. (2013) and Mechie et al. (2019) inferred eclogitization of the lower crust of segment 1 and that this lower crust hosts the band of intermediatedepth earthquakes. In our tomogram, we interpret $L 1$ as the lower crust and $H 1$ as the mantle lithosphere of the Asian slab (Fig. 3A).

The aseismic mid-crustal LVZ PL (Fig. 3A-C and 3E) may represent a heated rock volume, for example developed by excess radiogenic heat production in the thickened crust, viscous dissipation due to ongoing continental collision (e.g. Bird et al., 1975; Burg \& Gerya, 2005) or accumulation of slab-derived fluids (Mechie et al., 2019). We can exclude anisotropy effects for $P L$, as seismic ray directions are well distributed (Figs. S6-S9) and local shear-wave splitting measurements show only short delay times for the crust (Kufner, Eken, et al., 2018). Synthetic tests (Figs. S10a and S10b) and the detection of $P L$ with surface wave tomography preclude vertical smearing from the anomalies below (W. Li et al., 2018). Most importantly, we consider heating due to asthenospheric inflow, as would be expected in the hanging wall of a S-dipping subduction zone, as unlikely, because the tomogram does not show a LVZ - characteristic of an asthenospheric wedge - south of the seismic zone; in contrast, subcrustal $\mathrm{P}$-wave velocities are $>8 \mathrm{~km} / \mathrm{s}$ with large HVZs ( $>8.5 \mathrm{~km} / \mathrm{s}$ ) embedded (e.g. H3), indicating relatively cold and rigid lithospheric mantle there. 
The N-dip of the seismically active segment 2 can be traced $\sim 100 \mathrm{~km}$ along strike in narrowly-adjoining profiles between 75.1 to $75.9^{\circ} \mathrm{E}$ (Fig. S14g-j) and is robust with respect to the choice of the $V_{P}$ model (Fig. S13g-j). We interpret segment 2 as the eastern continuation of the S-dipping segment 1 of the Asian slab, because of the similar depth extent of the seismic zone and the continuity of the underlying HVZ (Fig. 2; Figs. 3A, 3B, and 3G). The dip reversal suggests that the slab overturns below $\sim 80 \mathrm{~km}$ depth (Fig. 2; Fig. 3B). Overturning in turn indicates that a force acts normal to the slab, which we expect in the presence of a pushing indenter. We attribute the seismicity gap between segments 1 and 2 to a slab tear that may explain how the slab dip changes over a relatively short distance $(\sim 40 \mathrm{~km})$. In our interpretation, the Asian slab terminates in a seismicity cluster below the Kashgar-Yecheng Transfer System at $76.2^{\circ} \mathrm{E}$ (Fig. 2), where, in a delamination scenario, it would need to be torn off Tarim's lithosphere to the east, where it would have originally been attached to. If instead segment 2 is separated from segment 1 and forms a continuous unit with segment 3 , the Asian slab would terminate at $\sim 74.5^{\circ} \mathrm{E}$ and the along-strike correlation of seismicity and $H 1$ and $H 2$ between segments 1 and 2 would be a coincidence.

In the northwestern Kunlun, L3 and H3 dip ENE and descend from the base of the Pamir crust in front of segment 2, a geometry that is also imaged by receiver functions (Fig. S17; Xu et al., 2021). Together with the location of the seismicity band of segment 3 in front of segment 2, this geometry is inconsistent with a semicircular, amphitheaterlike continuation of the Asian slab below Kunlun, but requires association of seismicity and $L 3$ with another tectonic unit (see below).

The orientation of $\sigma_{1}$ at depth indicates that a $\mathrm{N} 13^{\circ} \mathrm{W}$ compressive stress field acts on the deep structure of the Pamir. The stress orientation is stable across the three segments (Fig. S16), although uncertainty for the individual segments may become significant, due to the varying data availability. In contrast to the observed compression, $\mathrm{N}-$ S extension should occur south of the slab (in segment 3), if deformation was governed by a narrow Asian slab rolling back northward (Z.-H. Li et al., 2016). We note that compressive stresses are sub-parallel to the $\mathrm{N} 12^{\circ} \mathrm{W}\left( \pm 8^{\circ}\right)$-oriented surface velocity of the southern and central Pamir crust (e.g. Zubovich et al., 2010; Ischuk et al., 2013; Metzger et al., 2020). Both are deflected about $15^{\circ}$ counterclockwise from the $\mathrm{N} 4^{\circ} \mathrm{E}$-oriented convergence direction between India and Asia (DeMets et al., 1994). Parallelism of the orientation of the southern and central Pamir's surface displacement between the SarezKarakul Fault System and the Kongur Extensional System with $\sigma_{1}$ at depth suggests that crustal movement is prescribed by the mantle stresses, with the mantle lithosphere dragging the overlying Pamir crust south of the Asian slab northward. For segments 1 and 2, parallelism of $\sigma_{1}$ and surface displacement vectors arises naturally if collision occurs at an indenter tip. In summary, the repeated detection of HVZ H3 south of the Asian slab (this study; Mechie et al., 2012; Sippl, Schurr, Tympel, et al., 2013) that excludes asthenospheric inflow above a back-rolling subduction zone, the overturned geometry of segment 2 indicated by a change in the dip of the seismic zone, and the NNW-SSE compressive stress field across the central and eastern Pamir at mantle depth (50-100 km) that is parallel to surface displacement support the presence of an indenter below the Pamir.

The indenter is most likely cratonic Indian lithosphere, because the Gondwana-terrane lithosphere of the central and southern Pamir and Karakorum terranes would be too weak to transmit enough force to delaminate and overturn the Asian slab (Kelly \& Beaumont, 2021). We locate the delamination front at the base of the rheologically weak mid-crustal LVZ PL (red line in Fig. 4), just north of the Asian slab. The present location and form of the Pamir and the Asian slab is in this interpretation governed by the shape of the indenter. Additional structural complexity, such as the location of slab tears or turn-overs, may be due to lateral changes in the strength of the indented Asian lithosphere or the along-strike variability of the indenter tip (Z.-H. Li et al., 2016; Kelly \& Beaumont, 2021). 
For example $P H$, which overlies a distinctive Moho bulge in segment 1 (Fig 3A; Schneider et al., 2019), may represent a lithosphere-scale anticline; in segment 1, the top of the indenter appears to rise higher than in segment 2 and in particular in segment 3 (Fig. 4).

The ENE-dipping Moho trough (Fig. S17; Xu et al., 2021) and $V_{P}$ anomalies (L3 and H3) can, in this scenario, be interpreted as Pamir crust and indenter mantle lithosphere that underthrust the Asian (Tarim) mantle lithosphere (Fig. 3C). The earthquakes may, as in the Asian slab, occur in thickened crust undergoing eclogitization (John et al., 2009; Incel et al., 2019). This crust is likely dragged to depth between the bulldozing indenter and the margin of the Tarim block. The stress field of the earthquakes inside the underthrusting crust $L 3$ indicates that it moves with the NNW-ward moving indenter and underthrusts the Tarim hanging wall at a highly oblique angle. As the receiver function and interpreted tomographic Moho both dip WSW beneath the northwestern Kunlun east of $L 3$ (Fig. 3C; Xu et al., 2021), we infer that Tarim underthrusts the northwestern Kunlun as well, building a stack of (from top to bottom) Kunlun-TarimPamir crust (Fig. 4C). This excess crust may be responsible for a positive anomaly in the isostatic gravity residual (20-mGal-contour in Fig. 2; Balmino et al., 2012) that flanks the northern edge of the Tibet plateau (Fig. 2, inset), and was interpreted to represent thrusting of Tarim crust under the western and central Kunlun (Wittlinger et al., 2004).

In concert with the lack of thinned hinterland crust (Schneider et al., 2019) the herein deduced configuration of the tectonic units and the transpressive stress field in the intermediatedepth seismic zone of segment 3 preclude subduction of Asia at its (almost) entire thickness (Burtman \& Molnar, 1993; Sobel et al., 2013). The detection of H3 that is likely linked to a HVZ at $\sim 200 \mathrm{~km}$ depth that has been imaged with teleseismic body and surface wave tomography and connects with the exposed Indian craton (C. Li et al., 2008; Agius \& Lebedev, 2013; van Hinsbergen et al., 2019), yields a coherent picture of a promontory of Indian mantle lithosphere that underthrusts the Karakorum and the southern and central Pamir plateau between the Sarez-Karakul Fault System and the Kongur Extensional System, more than $300 \mathrm{~km}$ beyond the Indus suture (Fig. 1). The narrow but far north reaching extent of the indenter in the Pamir suggests a strong along-strike segmentation of the northern rim of the Indian plate; it subducts under the Hindu-Kush (Kufner et al., 2021), indents in the Pamir (this study; Kufner et al., 2016) and has variable dip angles and locations beneath the rest of Tibet (e.g. Zhao et al., 2010).

\section{Conclusion}

The presence of an Indian mantle indenter can be inferred beneath the Pamir plateau through its high seismic velocities $\left(V_{P}>8.5 \mathrm{~km} / \mathrm{s}\right)$ and the compressional stress it exerts on the overturned Asian slab. It is the farthest underthrusting part of India and the only one that refuses to subduct along the entire India-Asia plate boundary. Its plateaudefining shape needs to be accurately represented in tectonic models and gives rise to questions about the characteristics of the continental margin before collision. The likely cratonic nature of the indenter demonstrates the behaviour of such lithosphere in a collision setting and can be used as a benchmark for geodynamic models.

\section{Acknowledgments}

We thank the drivers and field participants from the Institute of Tibetan Plateau Research, especially Hongbing Liu, who helped to organize the station deployment, Christian Sippl for sharing code and discussion and two anonymous reviewers for their helpful comments. Funded by the CaTeNA project of the German Federal Ministry of Science and Education (support codes 03G0878A and 03G0878B) and German Research Council (DFG) grant Ra 442/41. Seismic data was handled using obspy (Krischer et al., 2015) and pyrocko (Heimann et al., 2017). Figures were created with the help of the Generic Mapping Tools (Wessel et al., 2013) and maplotlib (Hunter, 2007), using scientific color- 
maps (Crameri et al., 2020). Part of the instruments were provided by GIPP of GFZ Potsdam. Seismic data are archived by GEOFON data center (https://doi.org/10.14470/ 3U7560589977, https://doi.org/10.14470/4U7561589984)

\section{References}

Agius, M. R., \& Lebedev, S. (2013). Tibetan and Indian lithospheres in the upper mantle beneath Tibet: Evidence from broadband surface-wave dispersion. Geochemistry, Geophysics, Geosystems, 14(10), 4260-4281.

Aldersons, F. (2004). Toward three-dimensional crustal structure of the Dead Sea region from local earthquake tomography. PhD thesis.

Balmino, G., Vales, N., Bonvalot, S., \& Briais, A. (2012). Spherical harmonic modelling to ultra-high degree of Bouguer and isostatic anomalies. Journal of Geodesy, 86(7), 499-520.

Bird, P., Toksöz, M. N., \& Sleep, N. H. (1975). Thermal and mechanical models of continent-continent convergence zones. Journal of Geophysical Research, $80(32), 4405-4416$.

Brace, W., \& Kohlstedt, D. (1980). Limits on lithospheric stress imposed by laboratory experiments. Journal of Geophysical Research: Solid Earth, 85(B11), $6248-6252$.

Burg, J.-P., \& Gerya, T. (2005). The role of viscous heating in Barrovian metamorphism of collisional orogens: thermomechanical models and application to the Lepontine Dome in the Central Alps. Journal of Metamorphic Geology, 23(2), 75-95.

Burtman, V. S., \& Molnar, P. H. (1993). Geological and geophysical evidence for deep subduction of continental crust beneath the Pamir (Vol. 281). Geological Society of America.

Comino, J. Á. L., Heimann, S., Cesca, S., Milkereit, C., Dahm, T., \& Zang, A. (2017). Automated full waveform detection and location algorithm of acoustic emissions from hydraulic fracturing experiment. Procedia engineering, 191, 697-702.

Crameri, F., Shephard, G. E., \& Heron, P. J. (2020). The misuse of colour in science communication. Nature communications, 11(1), 1-10.

DeMets, C., Gordon, R. G., Argus, D. F., \& Stein, S. (1994). Effect of recent revisions to the geomagnetic reversal time scale on estimates of current plate motions. Geophysical research letters, 21(20), 2191-2194.

Diehl, T., Deichmann, N., Kissling, E., \& Husen, S. (2009). Automatic S-wave picker for local earthquake tomography. Bulletin of the Seismological Society of America, 99(3), 1906-1920.

Fan, G., Ni, J. F., \& Wallace, T. C. (1994). Active tectonics of the Pamirs and Karakorum. Journal of Geophysical Research: Solid Earth, 99(B4), 71317160 .

Heimann, S., Kriegerowski, M., Isken, M., Cesca, S., Daout, S., Grigoli, F., .. others (2017). Pyrocko-An open-source seismology toolbox and library. GFZ Data Services. doi: 10.5880/GFZ.2.1.2017.001

Hunter, J. D. (2007). Matplotlib: A 2D graphics environment. Computing in Science \& Engineering, 9(3), 90-95. doi: 10.1109/MCSE.2007.55

Incel, S., Hilairet, N., Labrousse, L., John, T., Deldicque, D., Ferrand, T., ... Schubnel, A. (2017). Laboratory earthquakes triggered during eclogitization of lawsonite-bearing blueschist. Earth and Planetary Science Letters, 459, 320331.

Incel, S., Labrousse, L., Hilairet, N., John, T., Gasc, J., Shi, F., ... others (2019). Reaction-induced embrittlement of the lower continental crust. Geology, 47(3), $235-238$. 
Ischuk, A., Bendick, R., Rybin, A., Molnar, P., Khan, S. F., Kuzikov, S., ... others (2013). Kinematics of the Pamir and Hindu Kush regions from GPS geodesy. Journal of geophysical research: solid earth, 118(5), 2408-2416.

Jamtveit, B., Ben-Zion, Y., Renard, F., \& Austrheim, H. (2018). Earthquakeinduced transformation of the lower crust. Nature, 556(7702), 487-491.

John, T., Medvedev, S., Rüpke, L. H., Andersen, T. B., Podladchikov, Y. Y., \& Austrheim, H. (2009). Generation of intermediate-depth earthquakes by self-localizing thermal runaway. Nature Geoscience, 2(2), 137-140.

Kelly, S., \& Beaumont, C. (2021). Balanced Cross-Sections and Numerical Modeling of the Lithospheric-Scale Evolution of the Hindu Kush and Pamir. Journal of Geophysical Research: Solid Earth, 126(3), e2020JB020678.

Kita, S., Okada, T., Nakajima, J., Matsuzawa, T., \& Hasegawa, A. (2006). Existence of a seismic belt in the upper plane of the double seismic zone extending in the along-arc direction at depths of 70-100 km beneath NE Japan. Geophysical Research Letters, 33(24).

Krischer, L., Megies, T., Barsch, R., Beyreuther, M., Lecocq, T., Caudron, C., \& Wassermann, J. (2015). ObsPy: A bridge for seismology into the scientific Python ecosystem. Computational Science \& Discovery, 8(1), 014003.

Kufner, S.-K., Eken, T., Tilmann, F., Schurr, B., Yuan, X., Mechie, J., ... Schneider, F. (2018). Seismic anisotropy beneath the Pamir and the Hindu Kush: Evidence for contributions from crust, mantle lithosphere, and asthenosphere. Journal of Geophysical Research: Solid Earth, 123(12), 10-727.

Kufner, S.-K., Kakar, N., Bezada, M., Bloch, W., Metzger, S., Yuan, X., ... others (2021). The Hindu Kush slab break-off as revealed by deep structure and crustal deformation. Nature communications, 12(1), 1-11.

Kufner, S.-K., Schurr, B., Ratschbacher, L., Murodkulov, S., Abdulhameed, S., Ischuk, A., ... Kakar, N. (2018). Seismotectonics of the Tajik basin and surrounding mountain ranges. Tectonics, 37(8), 2404-2424.

Kufner, S.-K., Schurr, B., Sippl, C., Yuan, X., Ratschbacher, L., Ischuk, A., ... others (2016). Deep India meets deep Asia: Lithospheric indentation, delamination and break-off under Pamir and Hindu Kush (Central Asia). Earth and Planetary Science Letters, 435, 171-184.

Li, C., Van der Hilst, R. D., Meltzer, A. S., \& Engdahl, E. R. (2008). Subduction of the Indian lithosphere beneath the Tibetan Plateau and Burma. Earth and Planetary Science Letters, 274 (1-2), 157-168.

Li, W., Chen, Y., Yuan, X., Schurr, B., Mechie, J., Oimahmadov, I., \& Fu, B. (2018). Continental lithospheric subduction and intermediate-depth seismicity: Constraints from S-wave velocity structures in the Pamir and Hindu Kush. Earth and Planetary Science Letters, 482, 478-489.

Li, Z.-H., Liu, M., \& Gerya, T. (2016). Lithosphere delamination in continental collisional orogens: A systematic numerical study. Journal of Geophysical Research: Solid Earth, 121(7), 5186-5211.

Liang, Y., Li, L., Liao, J., \& Gao, R. (2020). Interaction of the Indian and Asian plates under the Pamir and Hindu-Kush regions: Insights from 3-D shear wave velocity and anisotropic structures. Geochemistry, Geophysics, Geosystems, 21(8), e2020GC009041.

Lomax, A., Virieux, J., Volant, P., \& Berge-Thierry, C. (2000). Probabilistic earthquake location in 3D and layered models. In Advances in seismic event location (pp. 101-134). Springer.

Lu, S., Li, H., Zhang, C., \& Niu, G. (2008). Geological and geochronological evidence for the Precambrian evolution of the Tarim Craton and surrounding continental fragments. Precambrian Research, 160(1-2), 94-107.

Mechie, J., Schurr, B., Yuan, X., Schneider, F., Sippl, C., Minaev, V., ... others (2019). Observations of guided waves from the Pamir seismic zone provide additional evidence for the existence of subducted continental lower crust. 
Tectonophysics, 762, 1-16.

Mechie, J., Yuan, X., Schurr, B., Schneider, F., Sippl, C., Ratschbacher, L., .. others (2012). Crustal and uppermost mantle velocity structure along a profile across the Pamir and southern Tien Shan as derived from project TIPAGE wide-angle seismic data. Geophysical Journal International, 188(2), 385-407.

Metzger, S., Ischuk, A., Deng, Z., Ratschbacher, L., Perry, M., Kufner, S.-K., ... Moreno, M. (2020). Dense GNSS profiles across the northwestern tip of the India-Asia collision zone: Triggered slip and westward flow of the Peter the First Range, Pamir, into the Tajik Depression. Tectonics, 39(2), e2019TC005797.

Metzger, S., Schurr, B., Ratschbacher, L., Sudhaus, H., Kufner, S.-K., Schöne, T., .. Bendick, R. (2017). The 2015 Mw7. 2 Sarez Strike-Slip Earthquake in the Pamir Interior: Response to the Underthrusting of India's Western Promontory. Tectonics, 36 (11), 2407-2421.

Pegler, G., \& Das, S. (1998). An enhanced image of the Pamir-Hindu Kush seismic zone from relocated earthquake hypocentres. Geophysical Journal International, 134(2), 573-595.

PMP International (Tajikistan). (2005). Tajikistan National Seismic Network. International Federation of Digital Seismograph Networks. Retrieved from http:// www.fdsn.org/doi/10.7914/SN/TJ doi: 10.7914/SN/TJ

Ringwood, A., \& Green, D. (1966). An experimental investigation of the gabbroeclogite transformation and some geophysical implications. Tectonophysics, 3(5), 383-427.

Rondenay, S., Abers, G. A., \& Van Keken, P. E. (2008). Seismic imaging of subduction zone metamorphism. Geology, 36(4), 275-278.

Schneider, F., Yuan, X., Schurr, B., Mechie, J., Sippl, C., Haberland, C., ... others (2013). Seismic imaging of subducting continental lower crust beneath the Pamir. Earth and Planetary Science Letters, 375, 101-112.

Schneider, F., Yuan, X., Schurr, B., Mechie, J., Sippl, C., Kufner, S.-K., .. others (2019). The crust in the Pamir: Insights from receiver functions. Journal of Geophysical Research: Solid Earth, 124(8), 9313-9331.

Schwab, M., Ratschbacher, L., Siebel, W., McWilliams, M., Minaev, V., Lutkov, V., ... others (2004). Assembly of the Pamirs: Age and origin of magmatic belts from the southern Tien Shan to the southern Pamirs and their relation to Tibet. Tectonics, 23(4).

SEISDMC. (2021). Data management centre of the China National Seismic Network at the Institute of Geophysics. China Earthquake Administration. doi: 10 $.11998 / \mathrm{SeisDmc} / \mathrm{SN}$

Sippl, C., Schurr, B., Tympel, J., Angiboust, S., Mechie, J., Yuan, X., .. others (2013). Deep burial of Asian continental crust beneath the Pamir imaged with local earthquake tomography. Earth and Planetary Science Letters, 384, $165-177$.

Sippl, C., Schurr, B., Yuan, X., Mechie, J., Schneider, F., Gadoev, M., ... others (2013). Geometry of the Pamir-Hindu Kush intermediate-depth earthquake zone from local seismic data. Journal of Geophysical Research: Solid Earth, $118(4), 1438-1457$.

Sobel, E. R., Chen, J., Schoenbohm, L. M., Thiede, R., Stockli, D. F., Sudo, M., \& Strecker, M. R. (2013). Oceanic-style subduction controls late Cenozoic deformation of the Northern Pamir orogen. Earth and Planetary Science Letters, $363,204-218$.

Thurber, C. H. (1983). Earthquake locations and three-dimensional crustal structure in the Coyote Lake area, central California. Journal of Geophysical Research: Solid Earth, 88(B10), 8226-8236.

Tullis, J., \& Yund, R. (1992). The brittle-ductile transition in feldspar aggregates: An experimental study. In International geophysics (Vol. 51, pp. 89-117). Else- 
vier.

van Hinsbergen, D. J., Lippert, P. C., Li, S., Huang, W., Advokaat, E. L., \& Spakman, W. (2019). Reconstructing Greater India: Paleogeographic, kinematic, and geodynamic perspectives. Tectonophysics, 760, 69-94.

Waldhauser, F., \& Ellsworth, W. L. (2000). A double-difference earthquake location algorithm: Method and application to the northern Hayward fault, California. Bulletin of the Seismological Society of America, 90(6), 1353-1368.

Wessel, P., Smith, W. H., Scharroo, R., Luis, J., \& Wobbe, F. (2013). Generic mapping tools: improved version released. Eos, Transactions American Geophysical Union, 94 (45), 409-410.

Wittlinger, G., Vergne, J., Tapponnier, P., Farra, V., Poupinet, G., Jiang, M., ... Paul, A. (2004). Teleseismic imaging of subducting lithosphere and Moho offsets beneath western Tibet. Earth and Planetary Science Letters, 221(1-4), $117-130$.

Xu, Q., Zhao, J., Yuan, X., Liu, H., Ju, C., Schurr, B., \& Bloch, W. (2021). Deep crustal contact between the Pamir and Tarim Basin deduced from receiver functions. Geophysical Research Letters.

Yuan, X., Schurr, B., Bloch, W., Xu, Q., \& Zhao, J. (2018). East Pamir seismic network. GFZ Data services. doi: 10.14470/3U7560589977

Yuan, X., Schurr, B., Kufner, S.-K., \& Bloch, W. (2018). Sarez Pamir aftershock seismic network. GFZ Data services. doi: 10.14470/4U7561589984

Yuan, X., Sobolev, S. V., Kind, R., Oncken, O., Bock, G., Asch, G., ... others (2000). Subduction and collision processes in the Central Andes constrained by converted seismic phases. Nature, 408(6815), 958-961.

Zhao, J., Yuan, X., Liu, H., Kumar, P., Pei, S., Kind, R., ... others (2010). The boundary between the Indian and Asian tectonic plates below Tibet. Proceedings of the National Academy of Sciences, 107(25), 11229-11233.

Zubovich, A. V., Wang, X.-q., Scherba, Y. G., Schelochkov, G. G., Reilinger, R., Reigber, C., ... others (2010). GPS velocity field for the Tien Shan and surrounding regions. Tectonics, 29(6). 


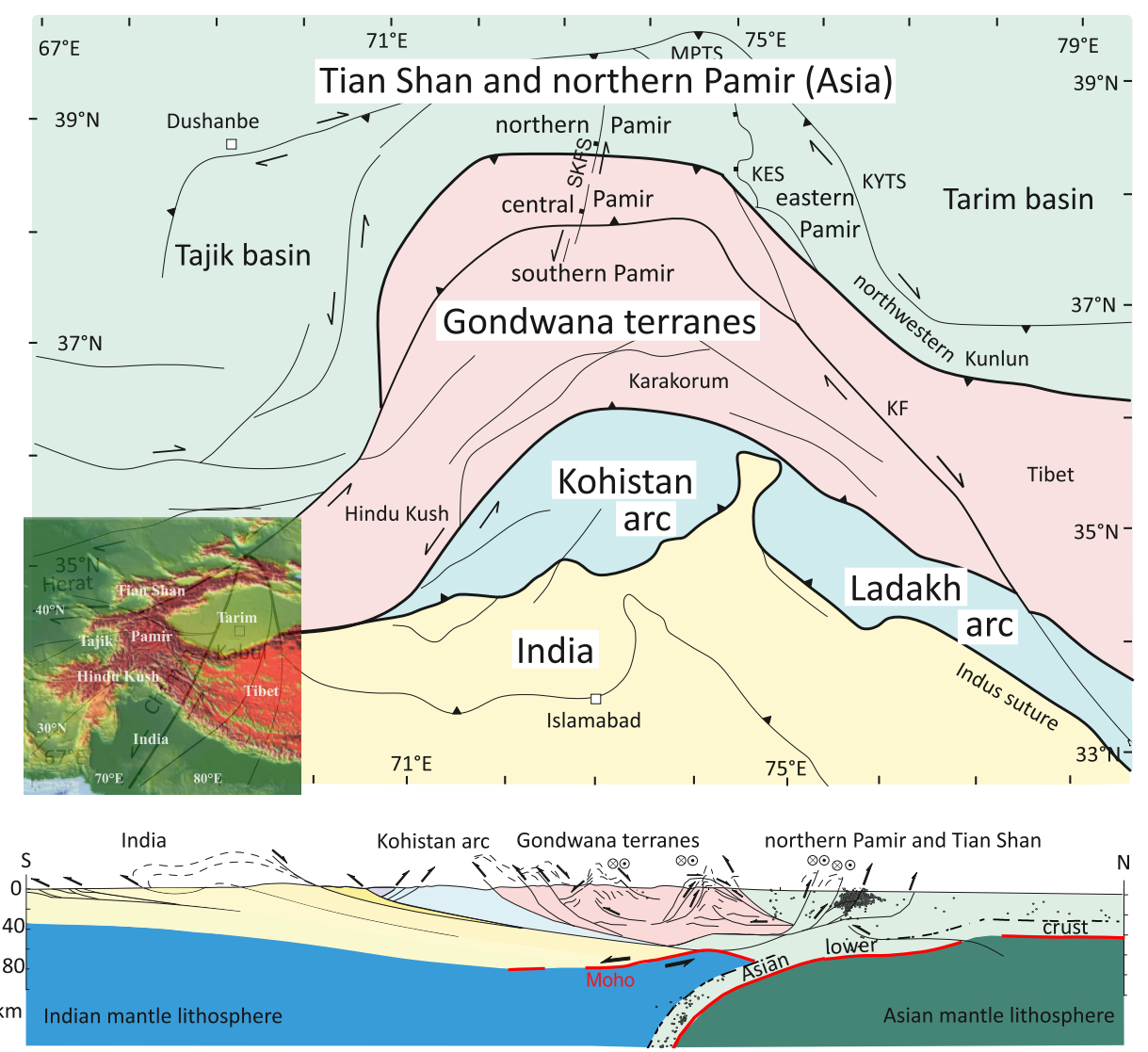

Figure 1. Tectonic units of the Pamir in map view and as a schematic cross section along $\sim 74^{\circ}$ E. Deep structure mostly from (Schneider et al., 2013). KES: Kongur Extensional System; KF: Karakorum Fault; KYTS: Kashgar-Yecheng Transfer System; MPTS: Main Pamir Thrust System; SKFS: Sarez-Karakul Fault System 


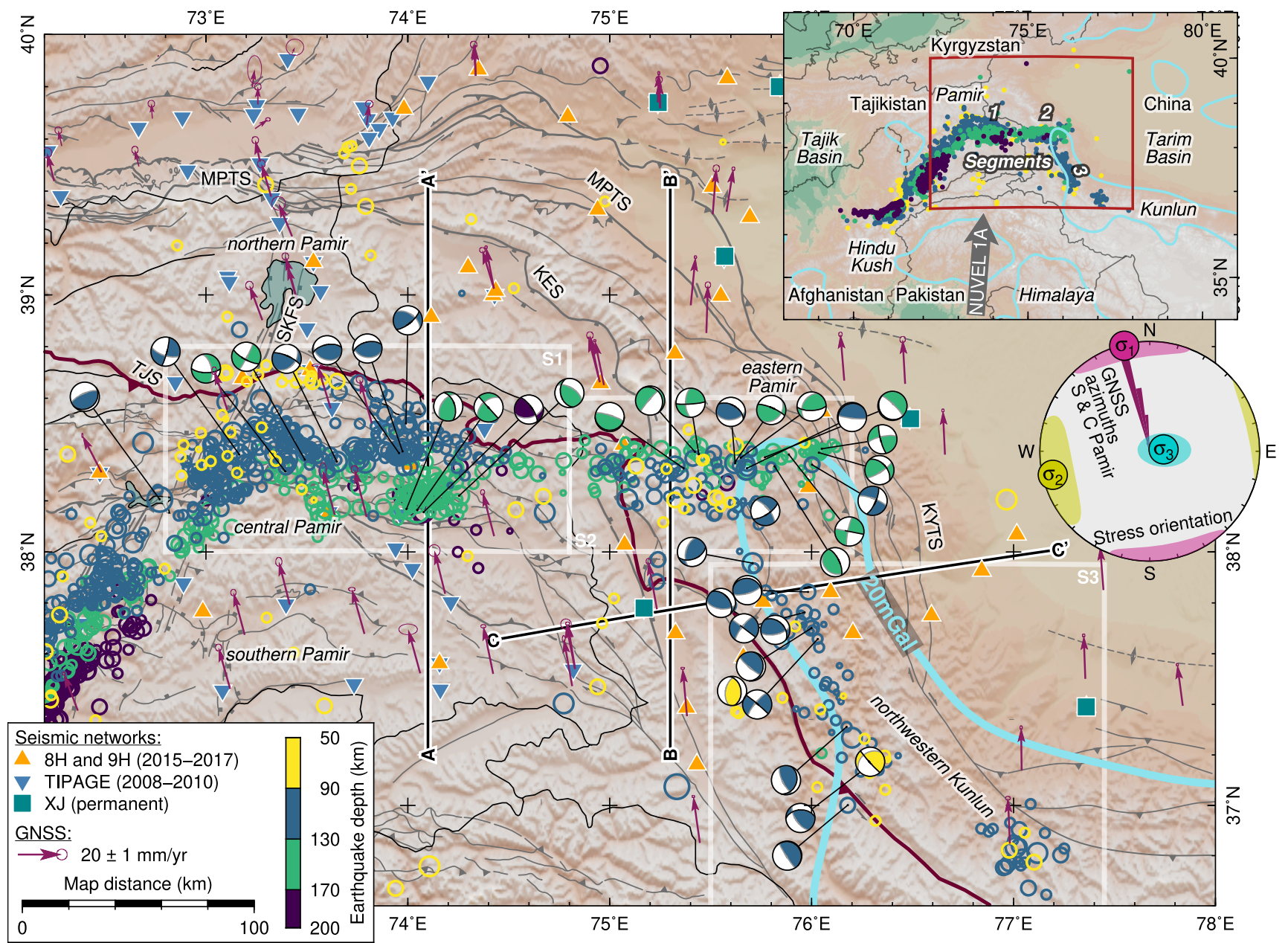

Figure 2. Seismotectonic map of the Pamir and northwestern Kunlun with seismic networks, seismicity at intermediate depth, focal mechanisms (black and gray nodal planes indicate fault and auxiliary plane preferred by stress inversion), global navigation satellite system (GNSS) velocity field (Ischuk et al., 2013; Zubovich et al., 2010), and 20mGal positive isostatic gravity anomaly (Balmino et al., 2012). Abbreviations as in Fig. 1. TJS: Tanymas-Jinsha suture; S1, S2, S3: segments 1 to 3; Map inset: Regional overview. Stereo-net inset: Lower hemisphere stereographic projection of stress directions and 95\% confidence ellipsoids (Fig. S16) and histogram of GNSS azimuths in the southern and central Pamir $\left(<38.8^{\circ} \mathrm{N}, 73-77^{\circ} \mathrm{E}, 5^{\circ}\right.$ bins $)$ 

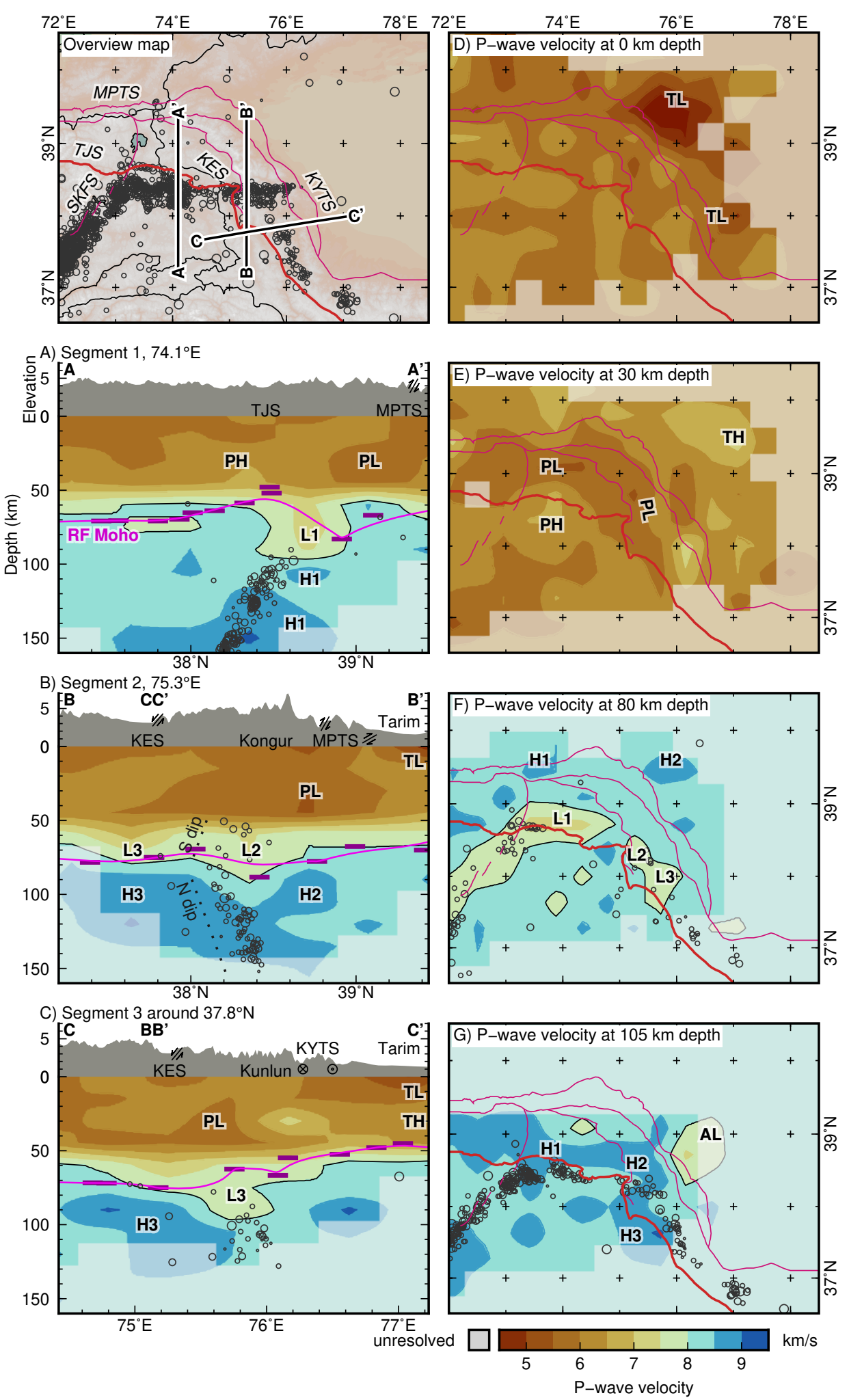

Figure 3. Sections through the tomogram. A-C) Profiles shown on overview map; swath width $\pm 25 \mathrm{~km}$; no vertical exaggeration in the depth profiles. Dark/light magenta: Receiver function Moho at individual stations and interpolated depth (Schneider et al., 2019; Xu et al., 2021). D-G) Horizontal sections. TH, PH, H1, H2, H3: high $V_{P}$ zones. TL, PL, L1, L2, L3, AL: low $V_{P}$ zones. Poorly resolved areas were masked based on a resolution test (Text S3). Relative $V_{P}$ anomalies with respect to the background model are shown in Fig. S11. 


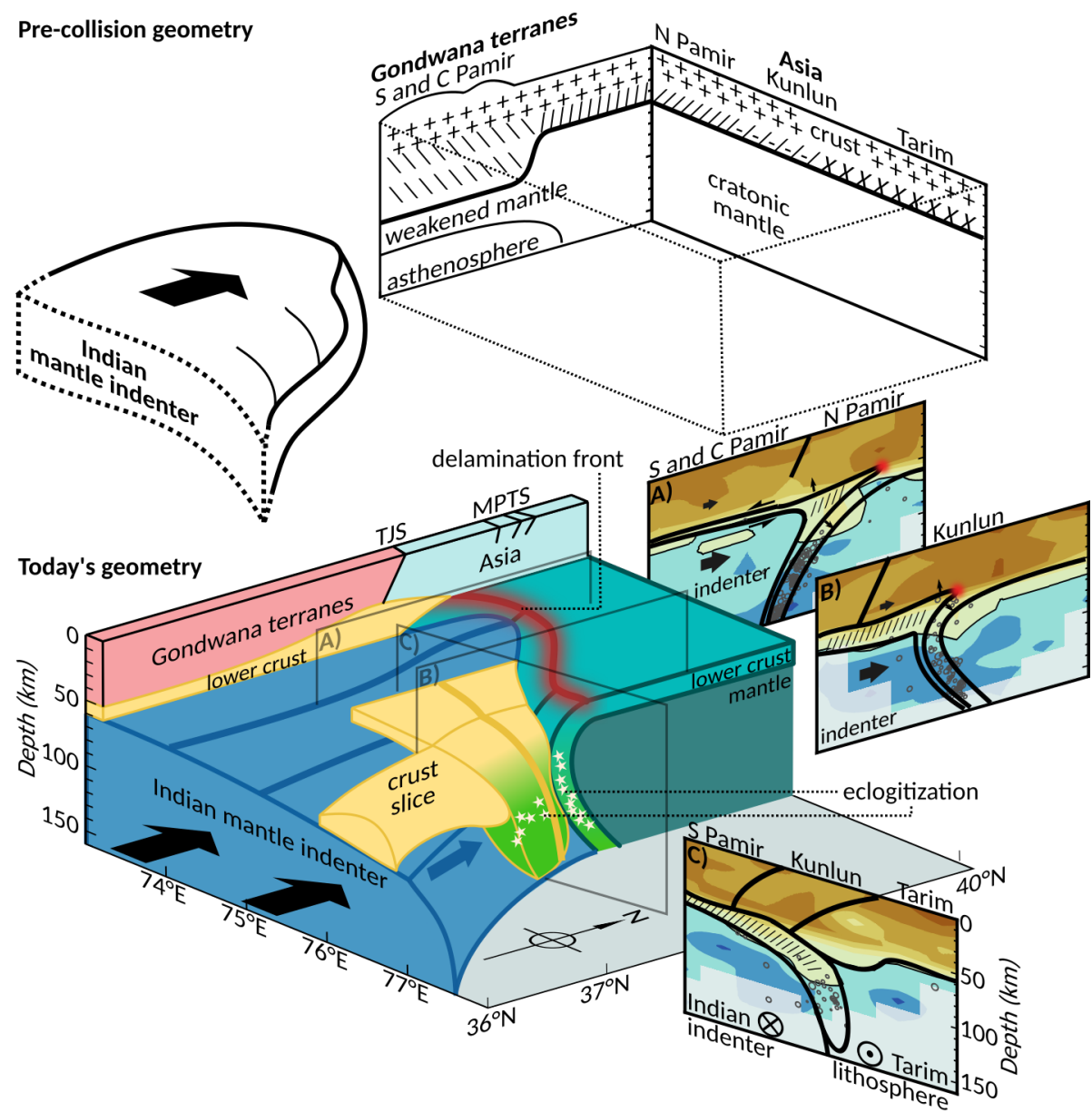

Figure 4. Structural interpretation of the $V_{P}$ structure, seismicity distribution, and stresses. Top: pre-collision geometry. Bottom: interpreted block diagram of the deep lithospheric structure beneath the Pamir and northwestern Kunlun. A-C) Interpreted cross sections of Fig. 3. '///' symbols mark the lower crust involved in the collision process. 
Supporting Information for "Structure and stress

= field of the lithosphere between Pamir and Tarim"

Wasja Bloch ${ }^{1}$, Bernd Schurr ${ }^{1}$, Xiaohui Yuan ${ }^{1}$, Lothar Ratschbacher ${ }^{2}$,

Sanaa Reuter ${ }^{2}$, Sofia-Katerina Kufner ${ }^{1,3}$, Qiang Xu ${ }^{4,5}$, Junmeng Zhao ${ }^{4,5}$

3

${ }^{1}$ GFZ German Research Centre for Geosciences, 14473 Potsdam, Germany

${ }^{2}$ Geologie, Technische Universität Bergakademie Freiberg, 09599 Freiberg, Germany

${ }^{3}$ British Antarctic Survey, Cambridge CB3 0ET, England

${ }^{4}$ Key Laboratory of Continental Collision and Plateau Uplift, Institute of Tibetan Plateau Research, Chinese Academy of Sciences,

Beijing 100101, China

${ }^{5}$ CAS Center for Excellence in Tibetan Plateau Earth Sciences, Beijing 100101, China

Contents of this file

1. Text S1 to Text S5

11

2. Figure S1 to Figure S17

Additional Supporting Information (Files uploaded separately)

1. Captions for Datasets S1 to S3

Corresponding author: Wasja Bloch (wbloch@eoas.ubc.ca). Now at: Earth, Ocean and Atmospheric Sciences, University of British Columbia, Vancouver, Canada. 
$\mathrm{X}-2$

BLOCH ET AL.: LITHOSPHER BETWEEN PAMIR AND TARIM

${ }_{14}$ Introduction This supporting information gives details of the processing steps briefly

${ }_{15}$ described in the main article. Additional figures, allowing to understand seismic network

16 sensitivity, as well as performance and stability of the 3-dimensional velocity model, are

${ }_{17}$ presented. The seismic event catalog, earthquake focal mechanism catalog, and seismic

${ }_{18}$ wave speed model, are published as separate data files and briefly described here. 
Text S1. Data We operated the East Pamir seismic network (FDSN code 8H; Yuan, Schurr, Bloch, et al., 2018) with 30 sites in the eastern Pamir, northwestern Kunlun, and northwestern Tarim basin between August 2015 and July 2017, and the Sarez-Pamir aftershock seismic network (FDSN code 9H Yuan, Schurr, Kufner, \& Bloch, 2018) with 10 sites in the central Pamir between February 2016 and July 2017. We used additional seismic waveform data from the Xinjiang regional seismic network (XJ; SEISDMC, 2021) and the Tajik National Seismic Network (FDSN network code TJ; SEISDMC, 2021).

\section{Text S2. Seismic Event Detection, Phase Picking, and Initial Localization}

We detected 39,309 seismic events, 10,900 of which at intermediate depth (>50 km), using the Lassie earthquake detector (Comino et al., 2017). We computed the moveout of smoothed, pulse-like image functions of the seismograms and stacked them for trial subsurface points on a rectangular grid of $100 \times 100 \times 10$ with a spacing of $10 \times 10 \times 30 \mathrm{~km}$ using the 1-D velocity model of (Sippl, Schurr, Yuan, et al., 2013). Peaks from coherent stacking of the image functions indicated the detection of a seismic event and an initial location and predicted $\mathrm{P}$ - and S-wave arrival times were used as a starting point for phase picking.

We automatically picked P-wave arrival times with MannekenPix (Aldersons, 2004), where initial picks from obspy's STA/LTA trigger and predicted picks from the detection routine were used as starting points; S-wave arrival times were picked with spicker (Diehl et al., 2009). Filter window lengths and positions for both pickers were calibrated from a set of 59 manually picked phase arrivals. After each arrival time picking run, events were located with hypo71 (Lee \& Lahr, 1972), and picks with the highest residuals were 
41

42

43

removed subsequently until the location root-mean-square misfit fell below a threshold of $2 \mathrm{~s}$ for P-waves only and $3 \mathrm{~s}$ for P-and S-waves combined. We then used a subset of 1,855 seismic events with the best constrained arrival-time picks to invert for a depth-dependent 1-D velocity model and static station corrections using velest (Kissling et al., 1994). We again relocated all events in this model and removed those arrival times that yielded a residual 5 times larger than the standard deviation of all residuals of a certain seismic phase on a certain station. In total, we located 29,795 seismic events in the crust and mantle this way.

\section{Text S3. Inversion for the Subsurface Velocity Field}

To derive a dataset suitable for tomographic inversion, we augmented the catalog with events from Sippl, Schurr, Tympel, et al. (2013) and used a spatially declustered set of 2,264 events from the combined catalog with a total of 38,423 well-constrained P- and 15,910 S-arrival times. Inversion for the 3-D subsurface P-wave velocity structure was conducted using simulps (Thurber, 1983).

The seismic velocity field was parameterized as gradients between a rectangular grid of nodes. After testing of various node configurations, we used a node spacing of $40 \mathrm{~km}$ in horizontal and $15 \mathrm{~km}$ in vertical direction (Figs. S1a and S2). The 1-D starting model was found by first inverting for the 1-D velocity gradients between vertical nodes and station corrections. Then, we constrained the velocities to increase with depth and that they do not exceed the velocity at $75-\mathrm{km}$ depth (Fig. S1a). The model space was explored with various damping parameters applied in the inversions (Fig. S1b). The final model was found by first inverting solely for the velocity structure and earthquake parameters, 
and then allowing for minor adjustments by letting non-modeled residuals be taken up by station corrections. The nodes of the input velocity model were modified with alternating anomalies of $\pm 5 \%$ in a checkerboard resolution test. Guided by the checkerboard test we masked regions where the resolving width function of the closest inversion node (Michelini \& McEvilly, 1991) was larger than 6 (Fig. S2 to S5).

We assessed the presence of smearing artifacts by computing synthetic travel times in our derived velocity model, inverting them again for the velocity structure from the original starting model and plotting the ray paths (Fig. S6 to S9).

We performed recovery tests for the anomalies that are most important to our interpretation by increasing (decreasing) the velocity of the 1-D starting model by $0.5 \mathrm{~km} / \mathrm{s}$ at the location of the interpreted high (low) velocity zones, computing synthetic travel times for this data set and adding random Gaussian noise with a standard deviation of $0.05,0.1,0.2$, or $0.4 \mathrm{~s}$ for pick classes $0,1,2$, and 3 . We then tried to recover the found velocity structure with the inversion strategy described above. The results are plotted in Fig. S10); they indicate the velocity anomalies $L 3, H 3, L 1, P H$, and $P L$ are adequately imaged by the inversion routine.

\section{Text S4. Location uncertainty and relative event relocation}

To focus on sub-crustal processes, we disregarded crustal earthquakes ( $<50-\mathrm{km}$ depth), which were dominated by a strong earthquake sequence and are confined to the upper $\sim 40-\mathrm{km}$ depth. We added intermediate-depth earthquakes to our seismicity catalog with at least 4 S-picks, which were previously excluded in the tomographic inversion. We then relocated all events with in the derived 3-D velocity model. To get a conservative estimate 
of the location uncertainty, we regridded the $3-\mathrm{D}$ gradient model on a $5 \mathrm{~km}$ grid, localized the events with NonLinLoc (Lomax et al., 2000) in the 3-D model, and report 2 times the square root of the diagonal elements of the covariance matrix as the $95 \%$ confidence intervals in longitude, latitude, and depth direction (Fig. S14). To assess the influence of the 3-D model on locations and location uncertainties, we also located the events in the 1-D model of Sippl, Schurr, Yuan, et al. (2013) (Fig. S13). We then relocated all events using the hypoDD algorithm (Waldhauser \& Ellsworth, 2000), using differential P- and S-wave catalog arrival times.

\section{Text S5. Focal Mechanisms and Stress Directions}

For 29 events, we observed P-wave first motion polarities and Cartesian P-to-S amplitude ratios on the $1 \mathrm{~Hz}$ highpass filtered seismograms and projected them to the focal sphere using the velocity model of Sippl, Schurr, Yuan, et al. (2013) using the workflow of Bloch, Schurr, Kummerow, Salazar, and Shapiro (2018). We then inverted for the earthquake focal mechanism using the HASH algorithm (Hardebeck \& Shearer, 2003; Bloch et al., 2018), and added 9 moment tensors of Kufner et al. (2016).

We used all focal mechanisms to invert for the deviatoric unit stress tensor by minimizing the misorientation between the earthquake slip vector and the predicted tangential traction on the fault plane. To resolve the nodal plane ambiguity, we first searched all stress tensors in angle intervals of $2^{\circ}$ and shape factor $\left(\Phi=\frac{\sigma_{2}-\sigma_{1}}{\sigma_{3}-\sigma_{1}}\right)$ intervals of 0.1 for the one that results in the lowest combined misfit, and selected the nodal planes with the lower misorientation as fault planes (Gephart \& Forsyth, 1984). We then inverted for the unit stress tensor using the slick algorithm and evaluated the uncertainty in the 
orientation using a bootstrapping approach (Fig. S16 Michael, 1987, 1984). We tested the stability of the found solutions by performing the inversion also separately for the three seismicity segments discussed in the main article (Fig. S16) 


\section{Data Set S1.}

\section{Bloch_et-al_2021_GRL_seismic_event_catalog.txt}

The seismic event catalog presented in the main article.

Seismic events from years 2008-2010 are relocated from Sippl, Schurr, Tympel, et al. $(2013)$

Coulumns are:

- Year, Month, Day, Hour, Minute, Second: Time of the seismic event (UTC)

- Timestamp: Time of the event in seconds since 1. January 1970 00:00:00 (UTC)

- Longitude, Latitude: Coordinated of the event location in degree

- Depth: Depth of the event in kilometer

- sigEW, sigNS, sigZ: 95\% confidence limits of the event location in latitudinal, longitudinal, and depth direction.

- Magnitude: Local magnitude of the seismic event

- P-picks, S-picks: Number of P- and S-wave arrival times used for event location

- method: Localization algorithm that yielded the reported location

Data Set S2. Bloch_et_al_2021_GRL_focal_mechanism_catalog.txt Coulumns are (compatible with Generic Mapping Tools psmeca -Sa):

1. Longitude of the event location in degree

2. Latitude of the event location in degree

3. Depth of the event in kilometer

4. Strike of the preferred fault plane in degree clockwise from north

5. Dip of the preferred fault plane in degree down from horizontal 
6. Rake of the slip vector on the fault plane in degree clockwise from strike direction

7. Local magnitude of the event

8. Unused placeholder

9. Unused placeholder

10. Time of the event (UTC)

Last 9 rows are from Kufner et al. (2016).

\section{Data Set S3.}

velocity_model.zip

Folder containing the nodes of the tomographic velocity model and scripts to extract and plot the published and custom profiles.

\section{References}

Aldersons, F. (2004). Toward three-dimensional crustal structure of the Dead Sea region from local earthquake tomography. PhD thesis.

Bloch, W., Schurr, B., Kummerow, J., Salazar, P., \& Shapiro, S. A. (2018). From slab coupling to slab pull: Stress segmentation in the subducting Nazca plate. Geophysical Research Letters, 45(11), 5407-5416.

Comino, J. Á. L., Heimann, S., Cesca, S., Milkereit, C., Dahm, T., \& Zang, A. (2017). Automated full waveform detection and location algorithm of acoustic emissions from hydraulic fracturing experiment. Procedia engineering, 191, 697-702.

Diehl, T., Deichmann, N., Kissling, E., \& Husen, S. (2009). Automatic S-wave picker for local earthquake tomography. Bulletin of the Seismological Society of America, $99(3), 1906-1920$. 
Gephart, J. W., \& Forsyth, D. W. (1984). An improved method for determining the regional stress tensor using earthquake focal mechanism data: application to the San Fernando earthquake sequence. Journal of Geophysical Research: Solid Earth, 89(B11), 9305-9320.

Hardebeck, J. L., \& Shearer, P. M. (2003). Using S/P amplitude ratios to constrain the focal mechanisms of small earthquakes. Bulletin of the Seismological Society of America, 93(6), 2434-2444.

Kissling, E., Ellsworth, W., Eberhart-Phillips, D., \& Kradolfer, U. (1994). Initial reference models in local earthquake tomography. Journal of Geophysical Research: Solid Earth, 99(B10), 19635-19646.

Kufner, S.-K., Schurr, B., Sippl, C., Yuan, X., Ratschbacher, L., Ischuk, A., ... others (2016). Deep India meets deep Asia: Lithospheric indentation, delamination and break-off under Pamir and Hindu Kush (Central Asia). Earth and Planetary Science Letters, 435, 171-184.

Lee, W. H. K., \& Lahr, J. C. (1972). HYPO71: A computer program for determining hypocenter, magnitude, and first motion pattern of local earthquakes. US Department of the Interior, Geological Survey, National Center for ....

Lomax, A., Virieux, J., Volant, P., \& Berge-Thierry, C. (2000). Probabilistic earthquake location in 3D and layered models. In Advances in seismic event location (pp. 101134). Springer.

Michael, A. J. (1984). Determination of stress from slip data: faults and folds. Journal of Geophysical Research: Solid Earth, 89(B13), 11517-11526. 
Michael, A. J. (1987). Use of focal mechanisms to determine stress: a control study. Journal of Geophysical Research: Solid Earth, 92(B1), 357-368.

Michelini, A., \& McEvilly, T. (1991). Seismological studies at parkfield. i. simultaneous inversion for velocity structure and hypocenters using cubic b-splines parameterization. Bulletin of the Seismological Society of America, 81(2), 524-552.

SEISDMC. (2021). Data management centre of the China National Seismic Network at the Institute of Geophysics. China Earthquake Administration. doi: 10.11998/ SeisDmc/SN

Sippl, C., Schurr, B., Tympel, J., Angiboust, S., Mechie, J., Yuan, X., .. others (2013). Deep burial of Asian continental crust beneath the Pamir imaged with local earthquake tomography. Earth and Planetary Science Letters, 384, 165-177.

Sippl, C., Schurr, B., Yuan, X., Mechie, J., Schneider, F., Gadoev, M., .. o others (2013). Geometry of the Pamir-Hindu Kush intermediate-depth earthquake zone from local seismic data. Journal of Geophysical Research: Solid Earth, 118(4), 1438-1457.

Thurber, C. H. (1983). Earthquake locations and three-dimensional crustal structure in the Coyote Lake area, central California. Journal of Geophysical Research: Solid Earth, 88(B10), 8226-8236.

Waldhauser, F., \& Ellsworth, W. L. (2000). A double-difference earthquake location algorithm: Method and application to the northern Hayward fault, California. Bulletin of the Seismological Society of America, 90(6), 1353-1368.

Xu, Q., Zhao, J., Yuan, X., Liu, H., Ju, C., Schurr, B., \& Bloch, W. (2021). Deep crustal contact between the Pamir and Tarim Basin deduced from receiver functions. 
$\mathrm{X}-12$ BLOCH ET AL.: LITHOSPHER BETWEEN PAMIR AND TARIM Geophysical Research Letters.

Yuan, X., Schurr, B., Bloch, W., Xu, Q., \& Zhao, J. (2018). East Pamir seismic network. GFZ Data services. doi: 10.14470/3U7560589977

Yuan, X., Schurr, B., Kufner, S.-K., \& Bloch, W. (2018). Sarez Pamir aftershock seismic network. GFZ Data services. doi: 10.14470/4U7561589984 


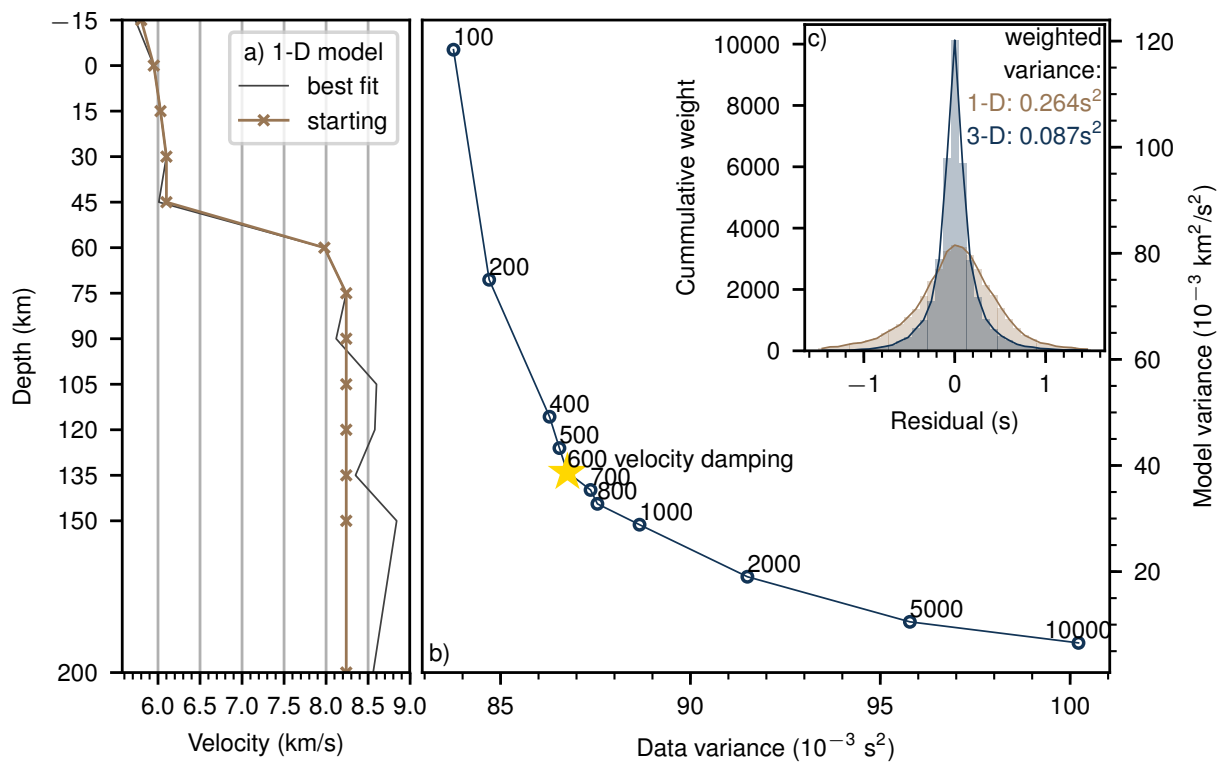

Figure S1. a) 1-D models. Best fit: Minimum misfit model after 1-D inversion with simulps with station corrections. Starting: Starting model for the 3-D inversion. We applied a positivity and a maximum velocity constraint to avoid pre-defining essential structures in the 3-D inversion b) L-curve to find optimal velocity damping parameter. Star: chosen value c) Reduction of arrival time residuals and variance from 1-D starting model to the presented 3-D model. 


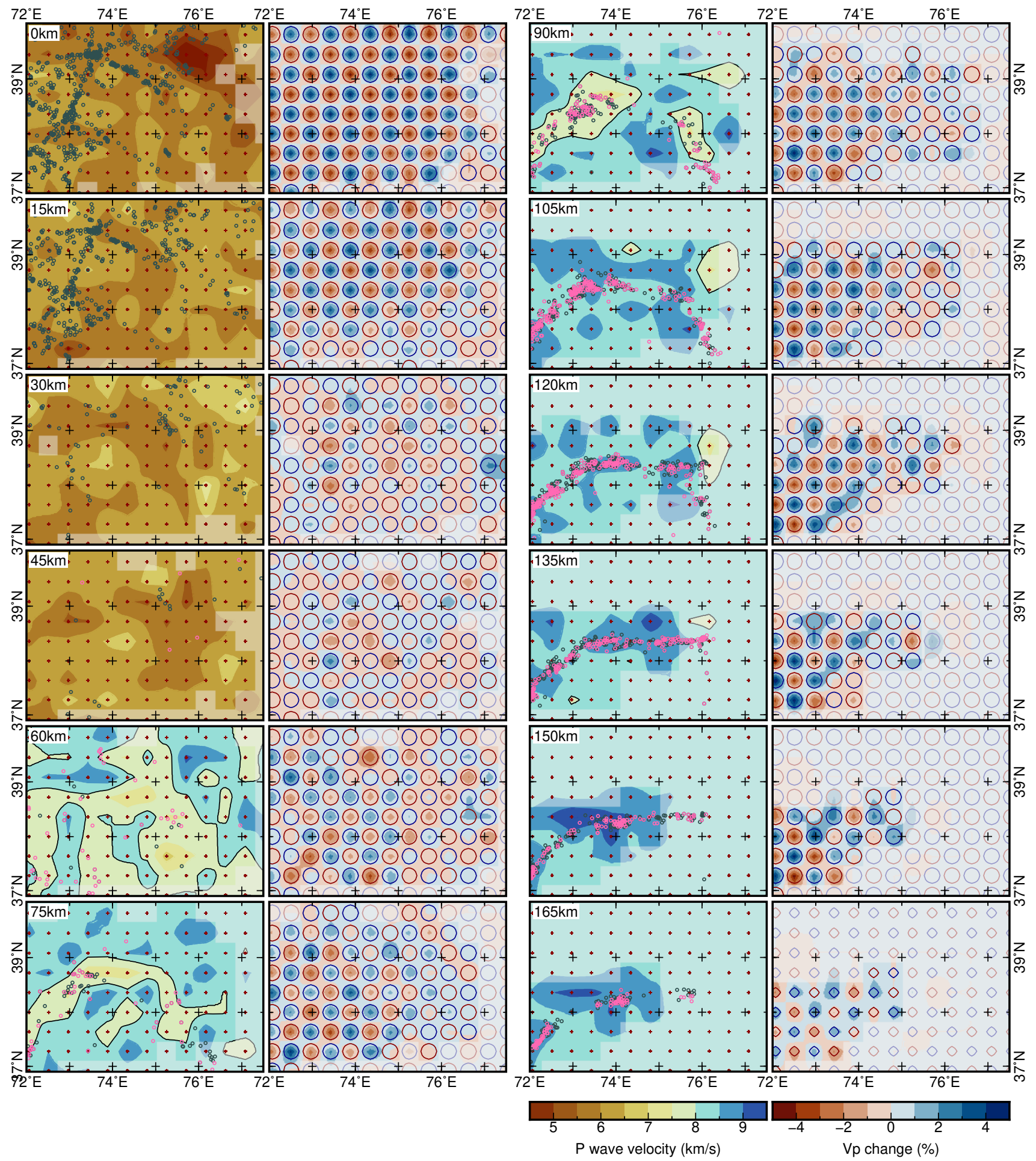

Figure S2. Horizontal slices through the tomogram at the node planes. Columns 1 and

3: Seismic velocities (colored background), grid nodes (red crosses), earthquakes used for tomographic inversion (gray circles), relocated earthquakes at intermediate depth (pink circles). Columns 2 and 4: Results of checkerboard recovery test: recovered model (colored background),

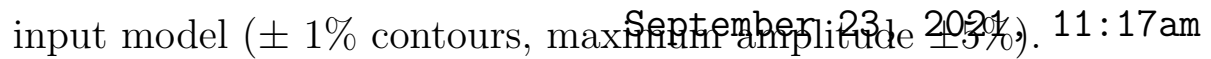




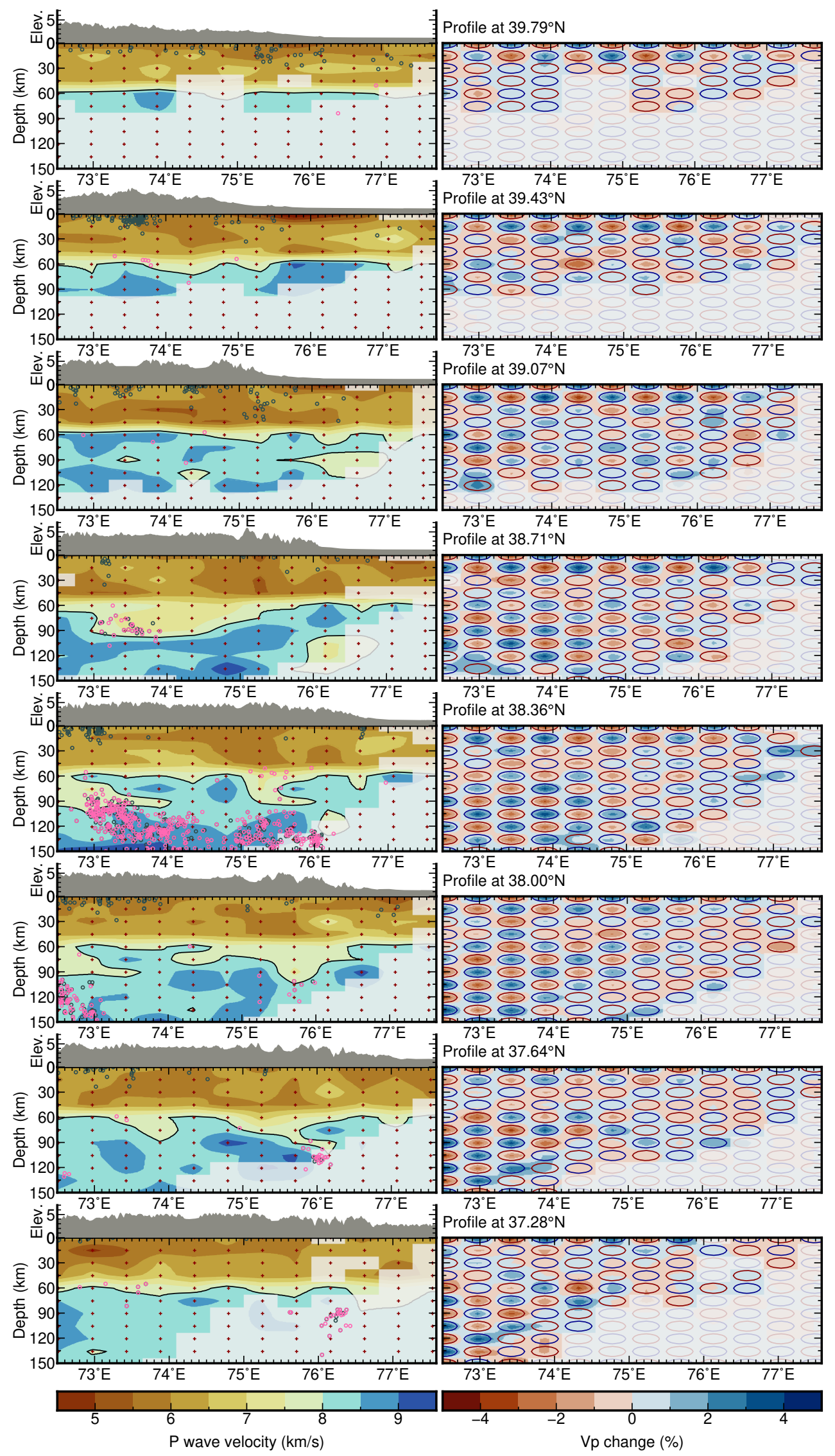

Figure S3. Same as Fig. S3, but weptember 23, 2021 west-east-profles. $11: 17$ am 

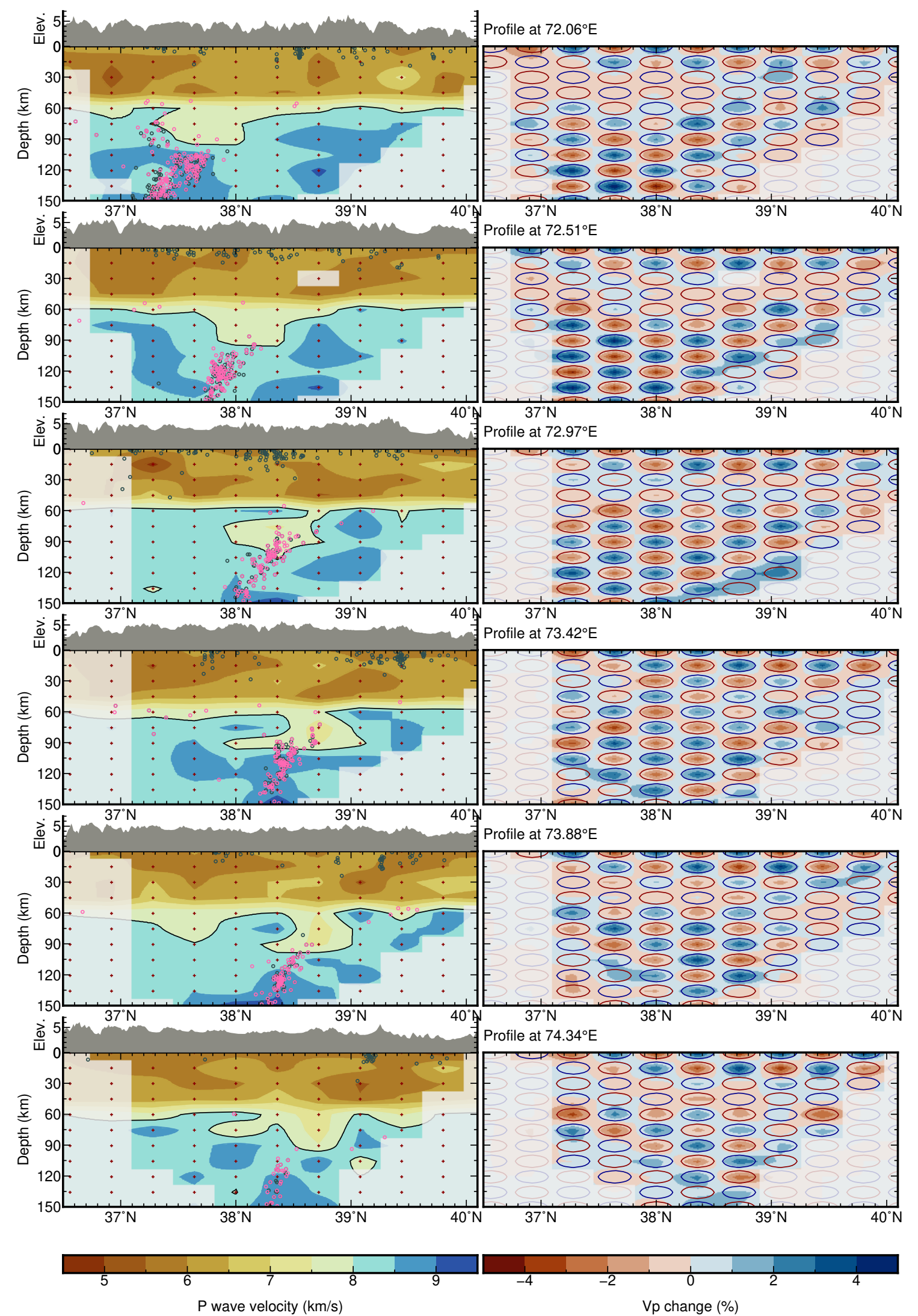

Figure S4. Same as Fig. S3, but with south-north-profiles. 


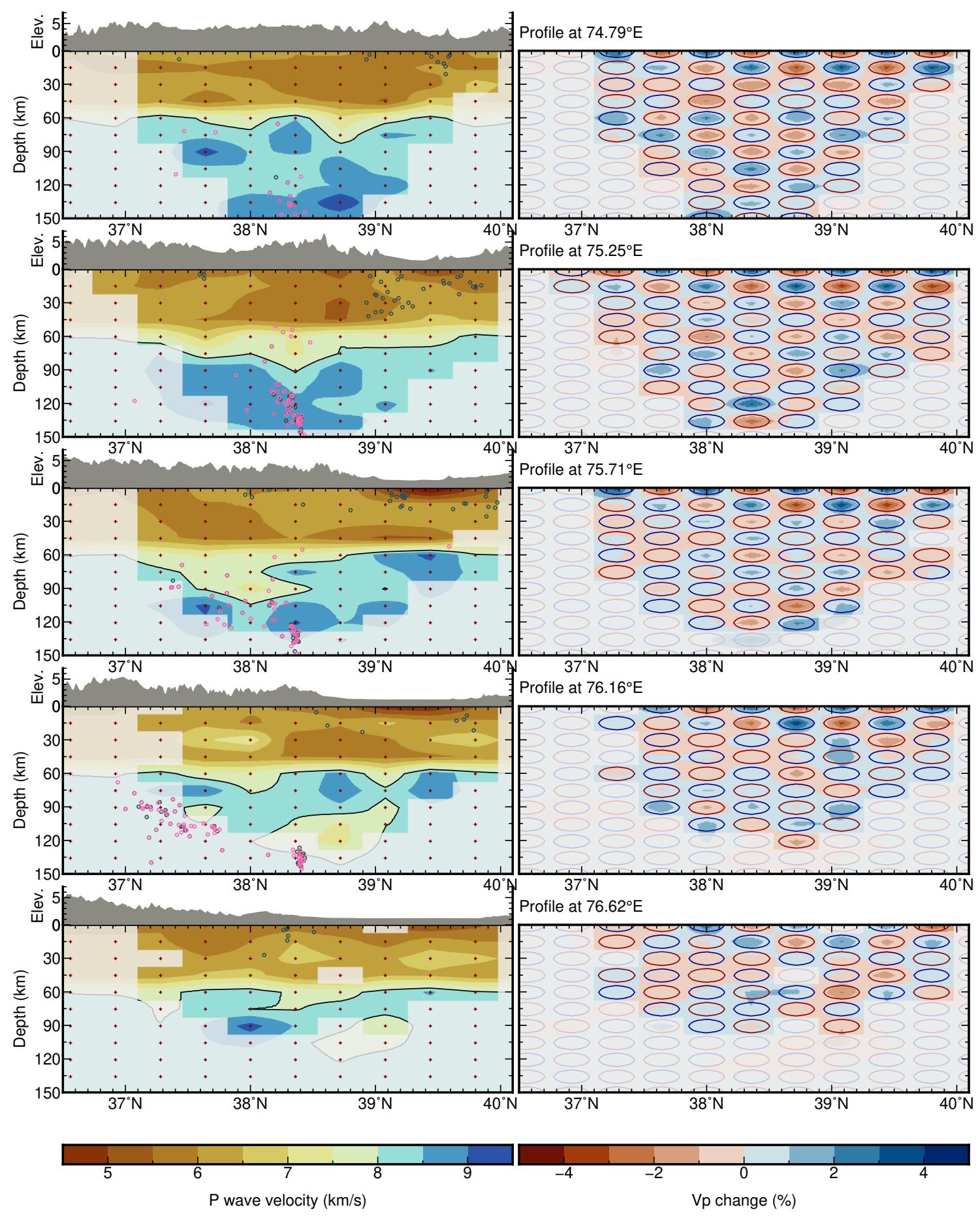

Figure S5. Fig. S4, continued 


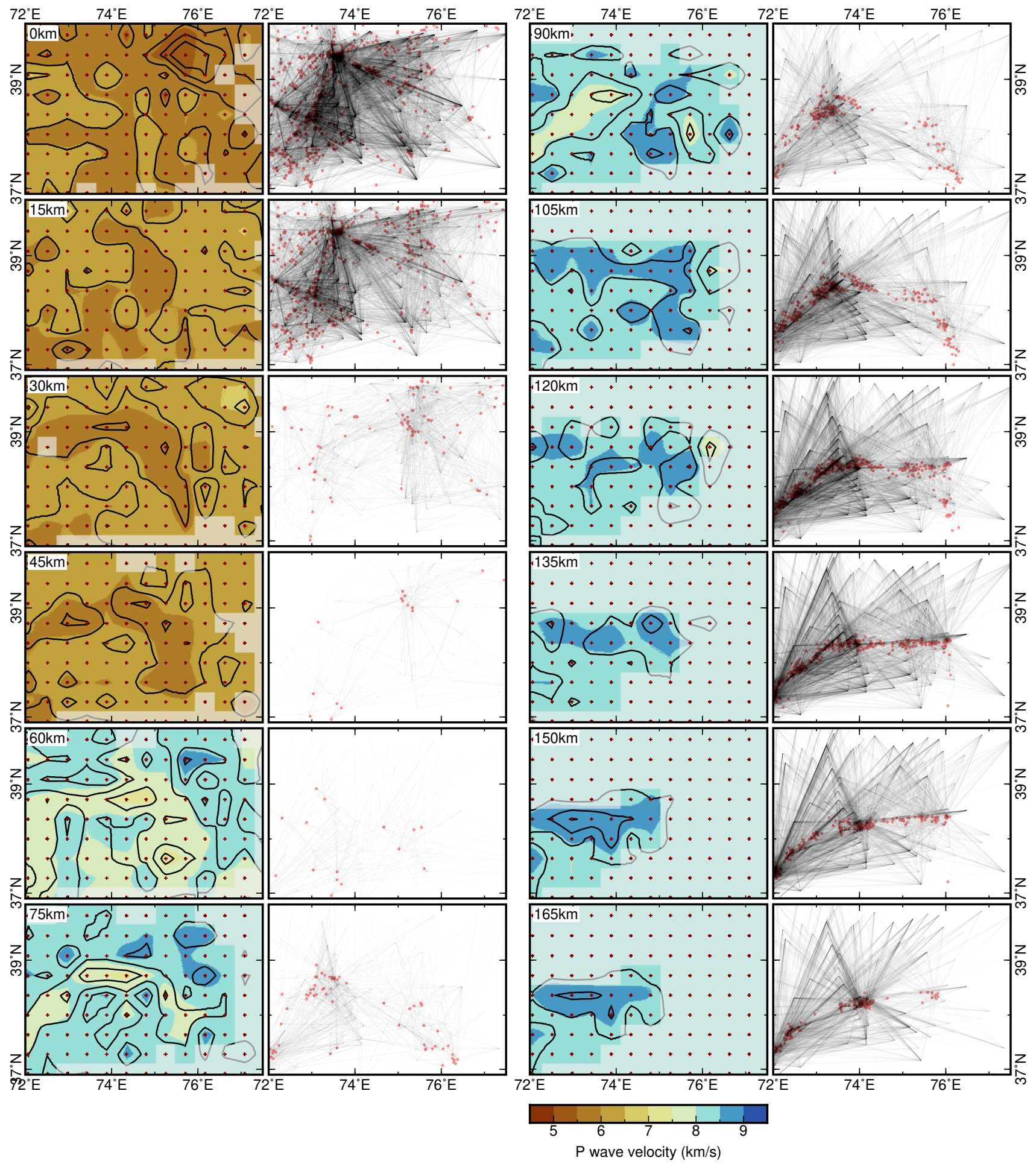

Figure S6. Horizontal slices at the node planes through recovery test of the tomographic inversion. Columns 1 and 3: Input model as in Fig. S2 (contours), and recovered model (colored background). Columns 2 and 4: Ray paths departing in the respective horizontal slice. 

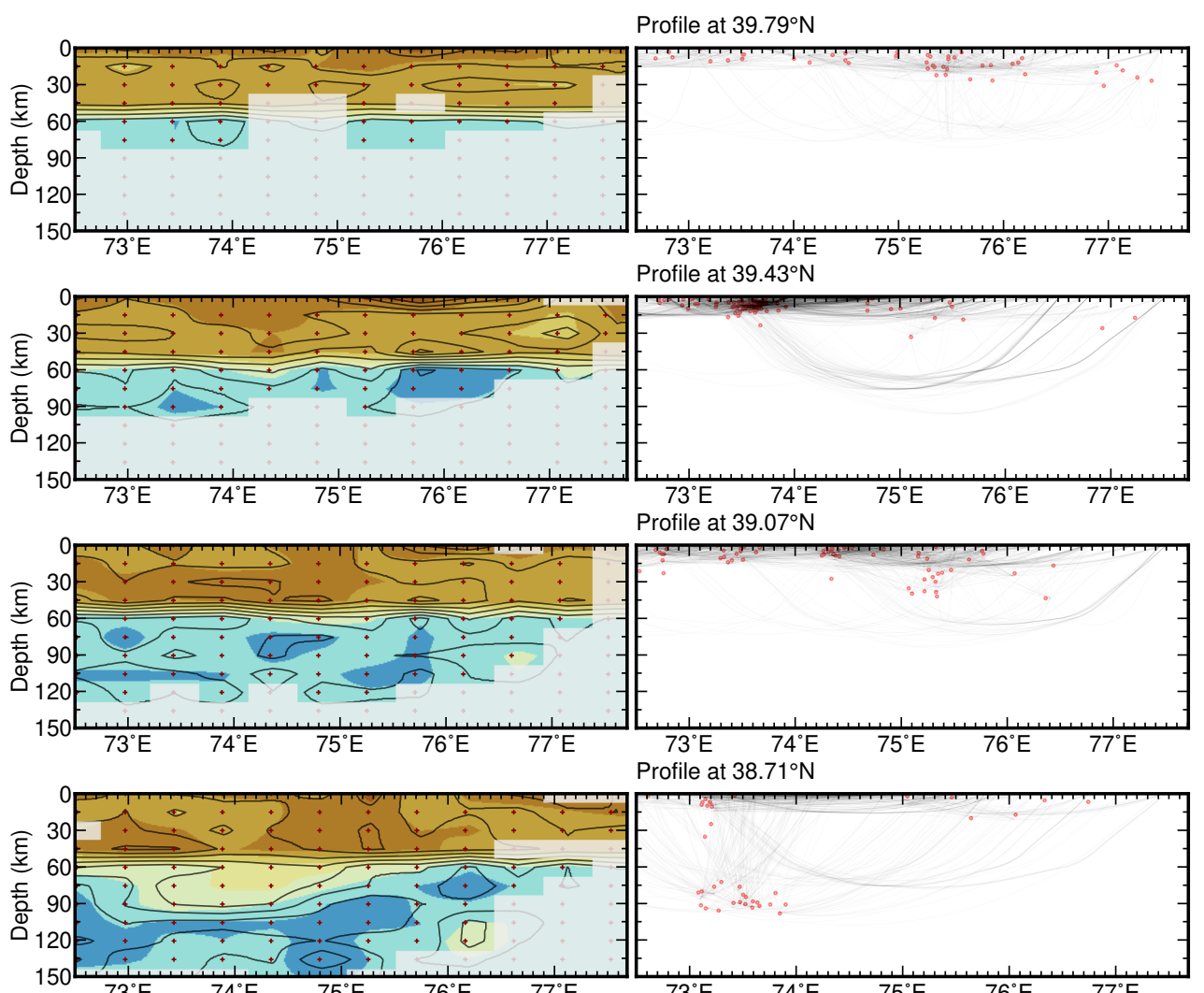

Profile at $38.71^{\circ} \mathrm{N}$
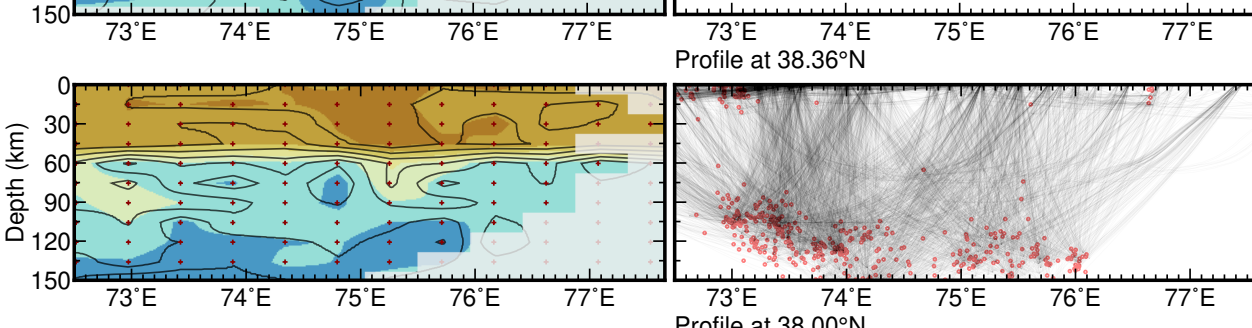

Profile at $38.36^{\circ} \mathrm{N}$
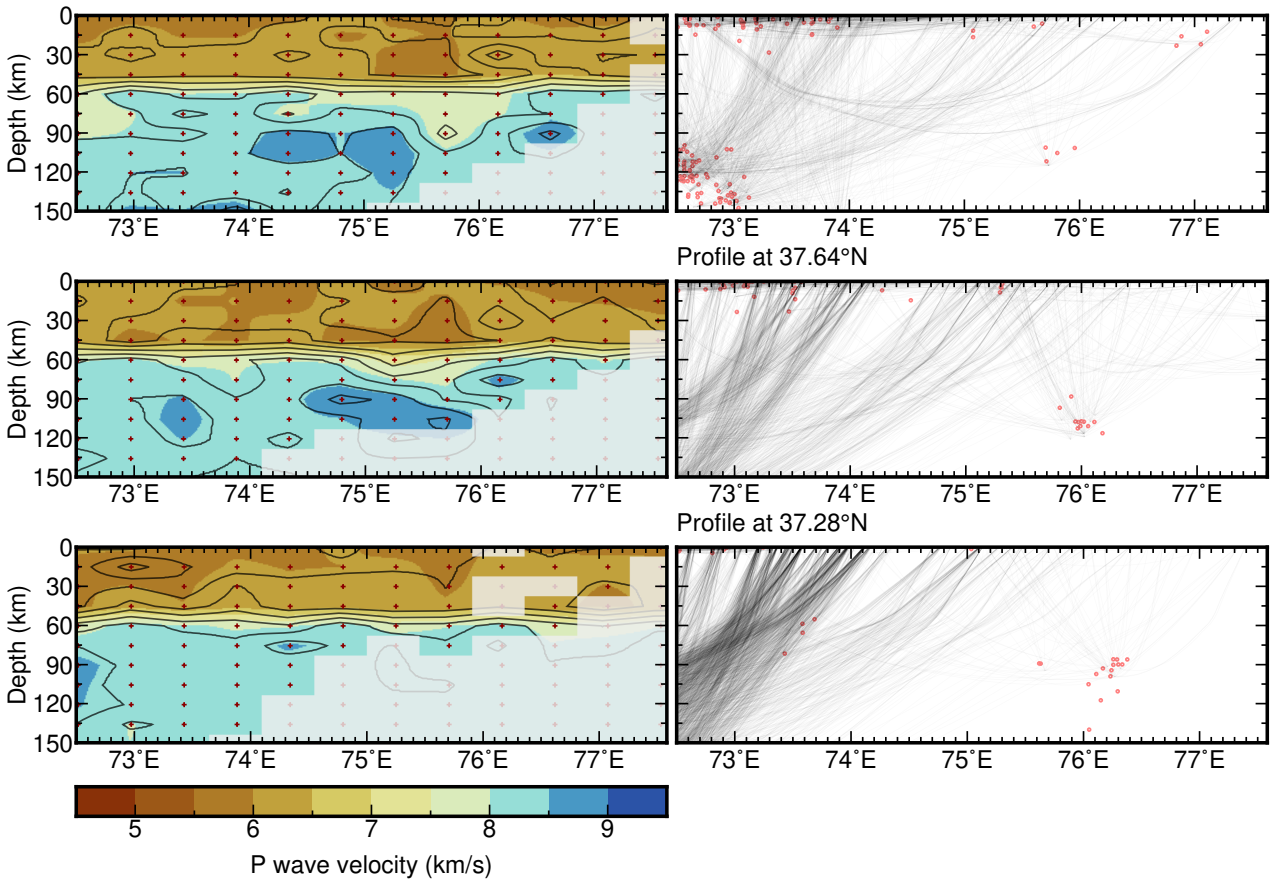

Figure S7. Same as Fig. S6, buteptemperst233st29fofiles!1:17am 

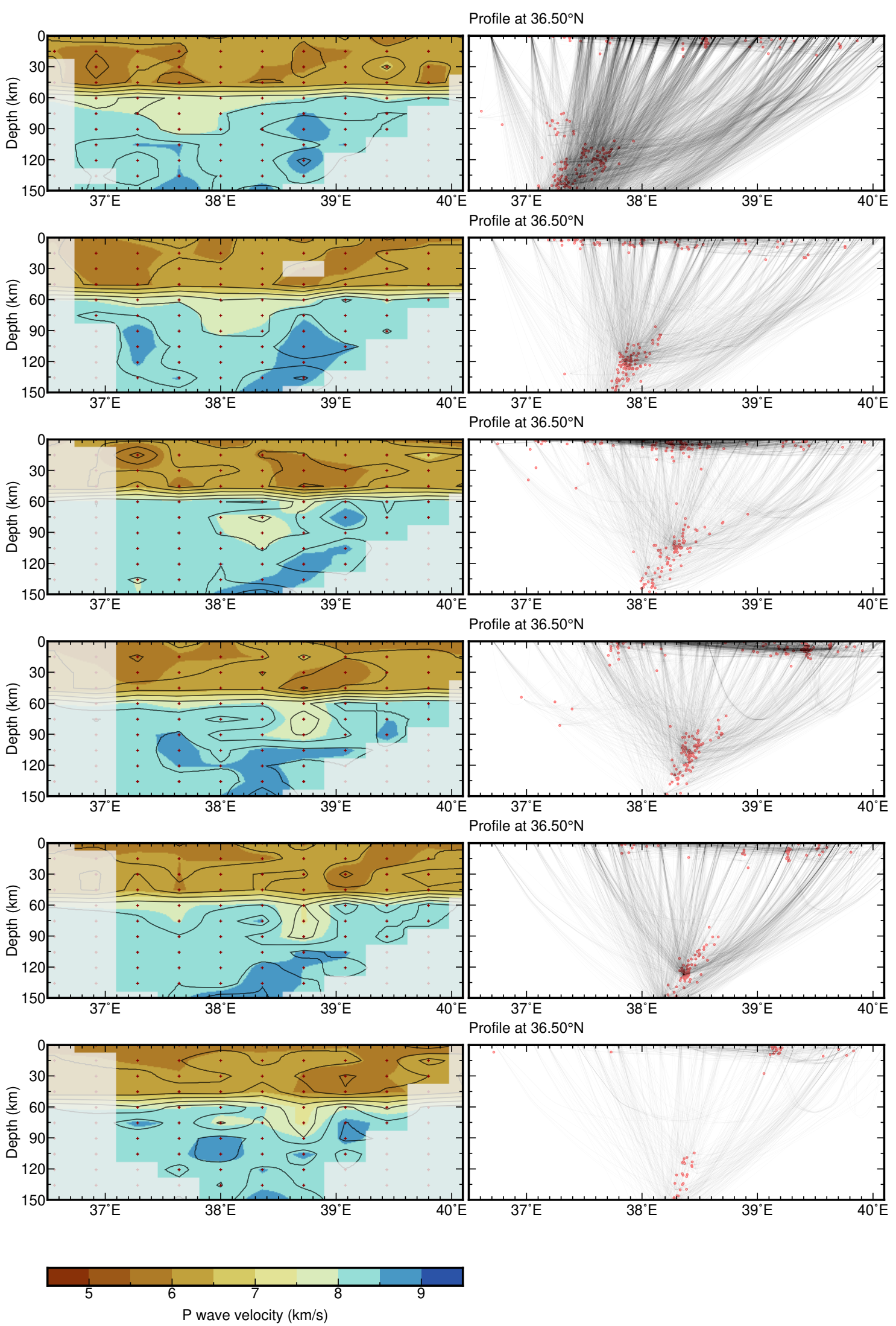

Figure S8. Same as Fig. S7, but with south-north-profiles.

September 23, 2021, 11:17am 

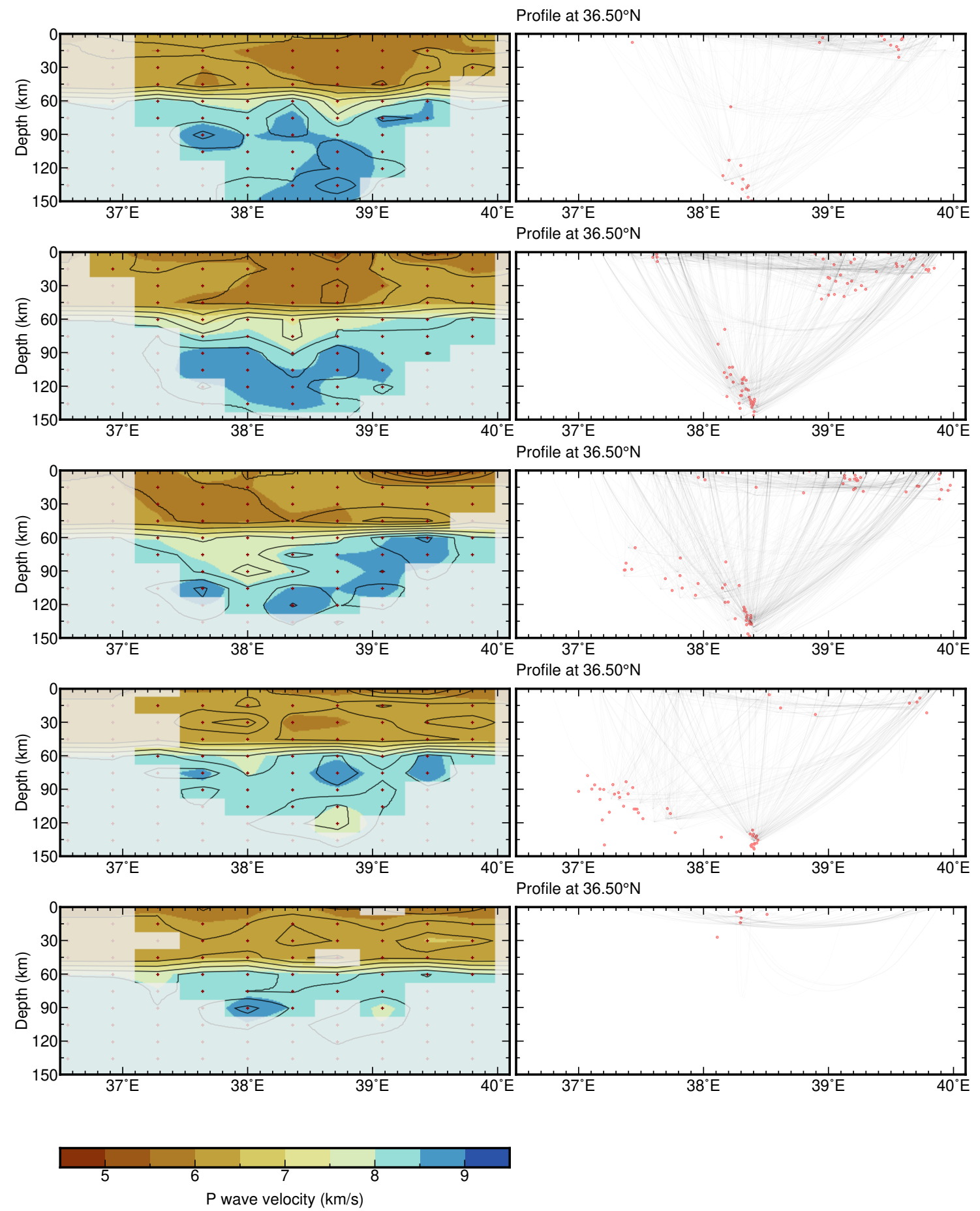

Figure S9. Fig. S8, continued 

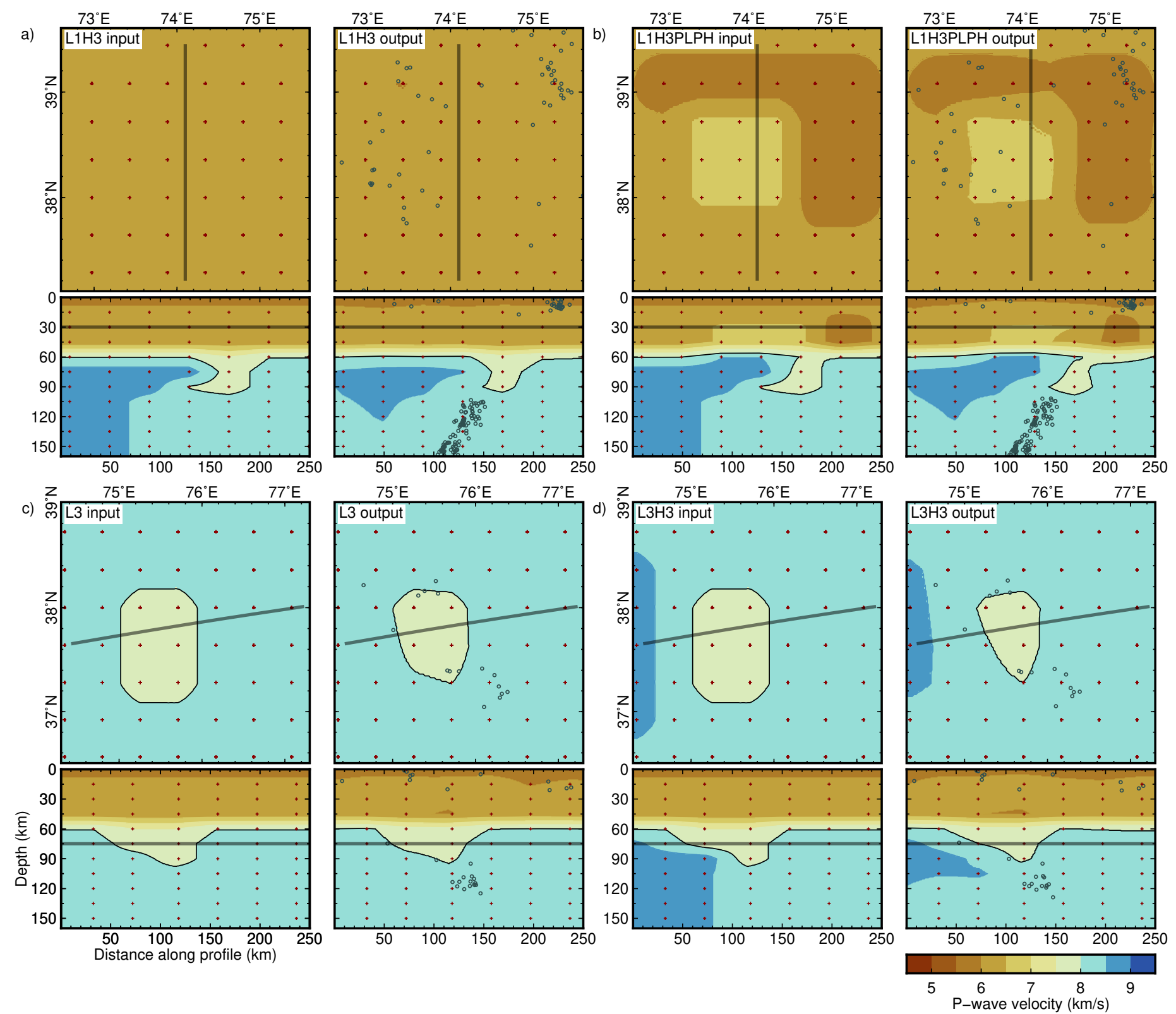

Figure S10. Summary of recovery tests for selected anomalies as close-ups of horizontal slices (top sub-panels) and profiles (bottom sub-panels) through the anomalies, as in Fig. 3 of the main text. Slice depth and profile location indicated as gray lines. Left subfigures: input anomalies. Right subfigures: recovered anomalies. (a) Anomalies L1 and H3. (b) Anomalies L1, H3, PL, and PH. (c) Anomaly L3 only. (d) Anomalies L3 and H3. 

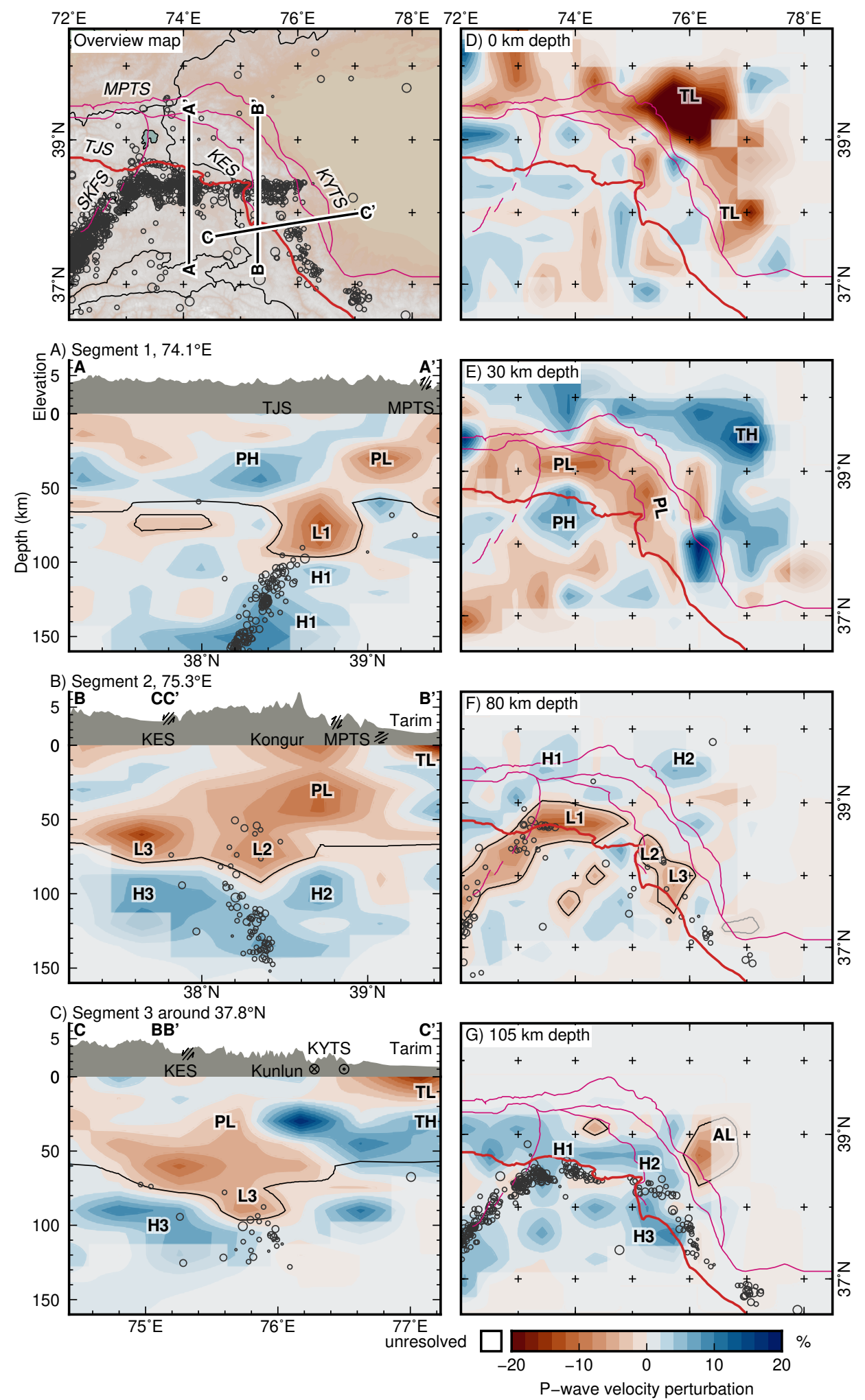

Figure S11. As Figure 3 of the main text, but showing velocity changes relative to the 1-D background model (Fig. S1a). Black line is the $8 \mathrm{~km} / \mathrm{s}$ contour. 


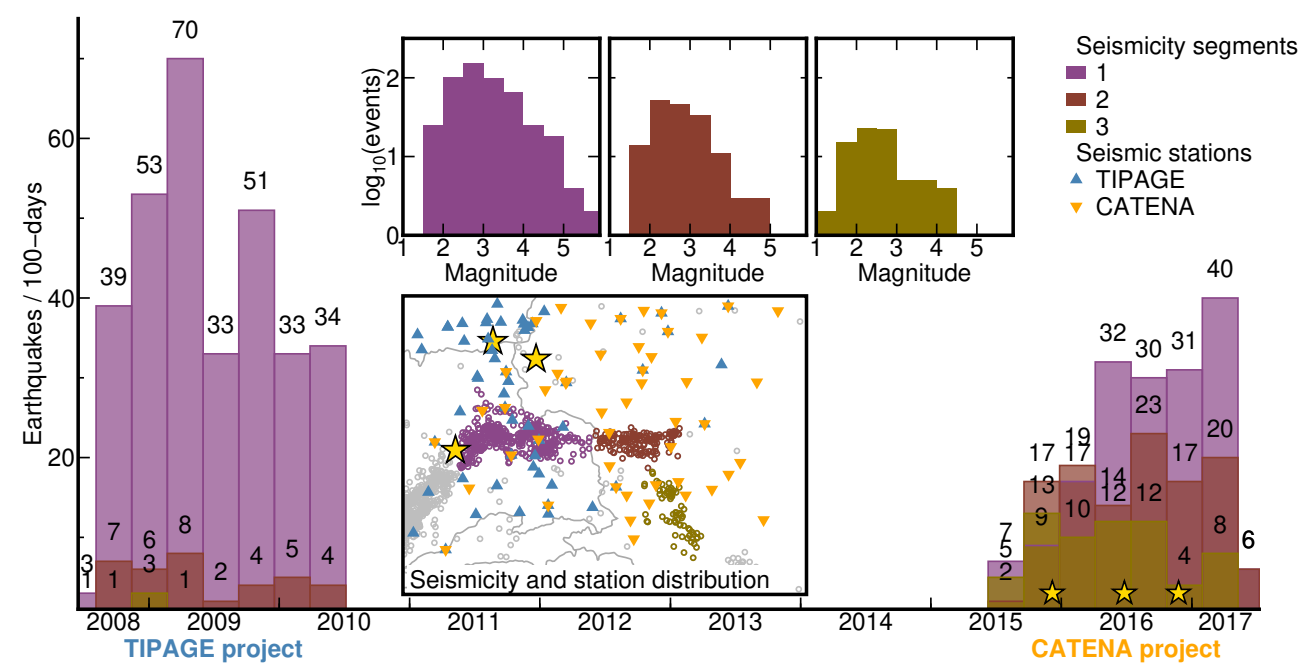

Figure S12. Seismicity rate, local event magnitudes, and station distribution for the three seismicity segments discussed in the main article. Stations of the TIPAGE project (2008-2010, blue) were located in the Tajik Pamir and covered the central segment. Stations of the CATENA project (2015-2017, orange), including networks 8H, 9H and XJ, were located in the Chinese Pamir and Tarim basin and covered segment 2 and 3. Additional stations were placed in the Tajik Pamir in February 2016. Aftershock sequences of strong earthquakes (stars) in December 2015, June 2016, and November 2016 represent seismic noise that lowered the detection capability of intermediate depth seismicity. Magnitudes of events that occur outside one of the networks (especially in segment 3) tend to be overestimated. Event rate in segment 1 is significantly higher compared to segment 2 and segment 3, despite the different network configuration and noise conditions. 


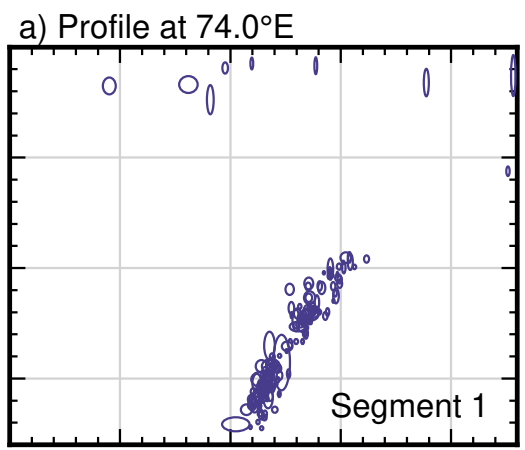

d) Profile at $74.6^{\circ} \mathrm{E}$

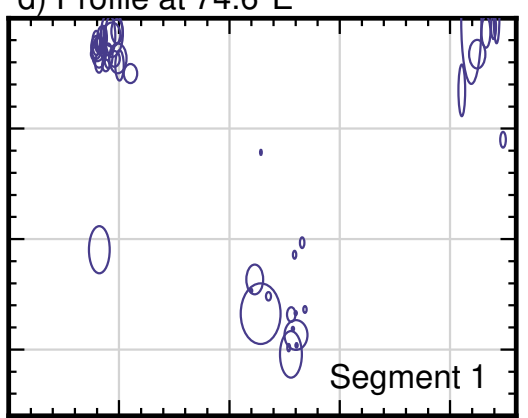

g) Profile at $75.2^{\circ} \mathrm{E}$
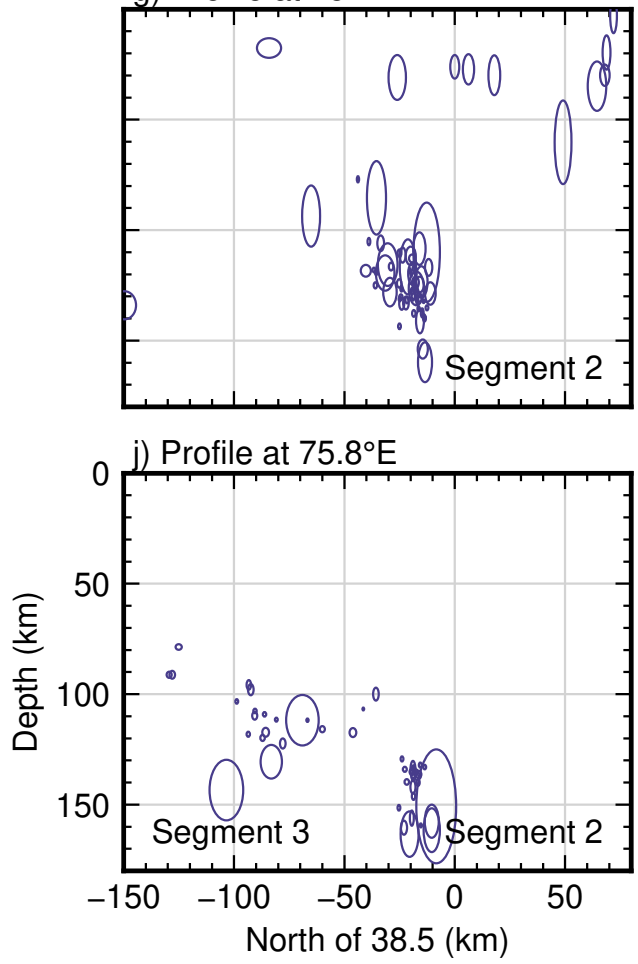

b) Profile at $74.2^{\circ} \mathrm{E}$

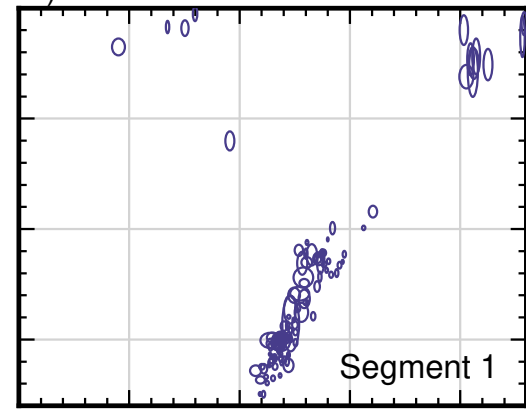

e) Profile at $74.8^{\circ} \mathrm{E}$

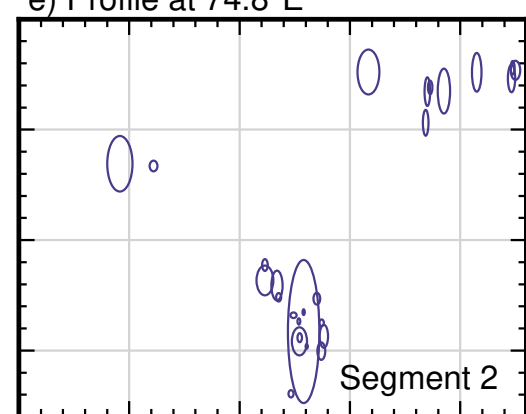

h) Profile at $75.4^{\circ} \mathrm{E}$

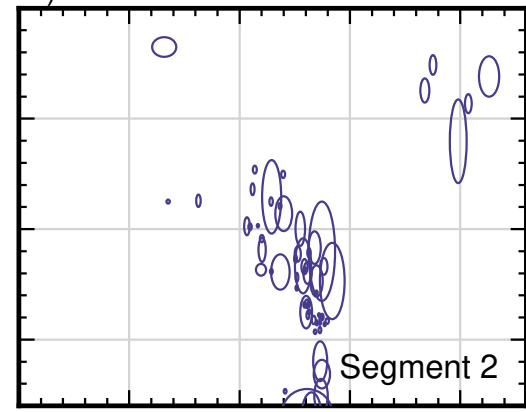

k) Profile at $76.0^{\circ} \mathrm{E}$

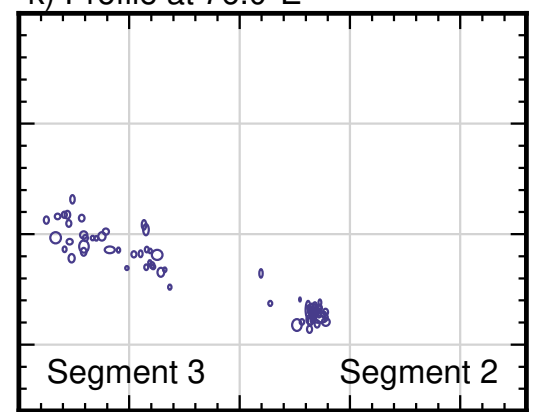

c) Profile at $74.4^{\circ} \mathrm{E}$

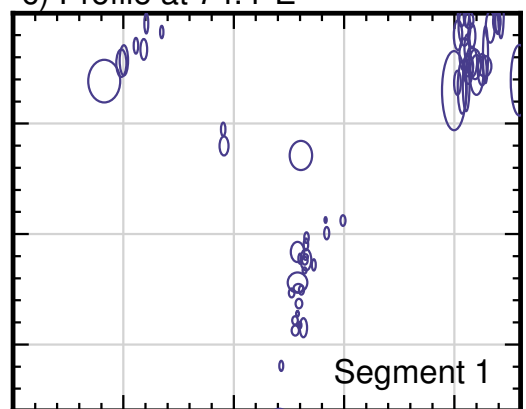

f) Profile at $75.0^{\circ} \mathrm{E}$

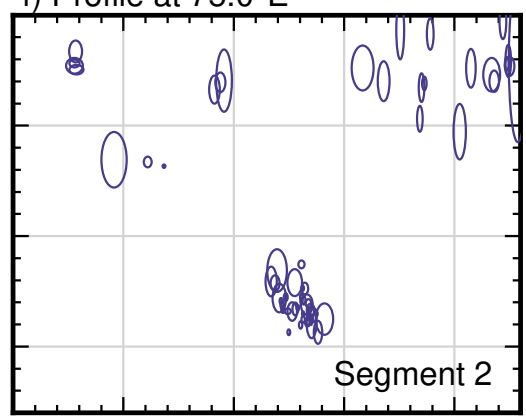

i) Profile at $75.6^{\circ} \mathrm{E}$

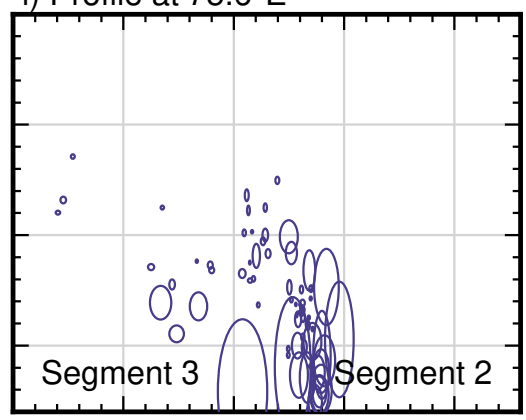

I) Profile at $76.2^{\circ} \mathrm{E}$

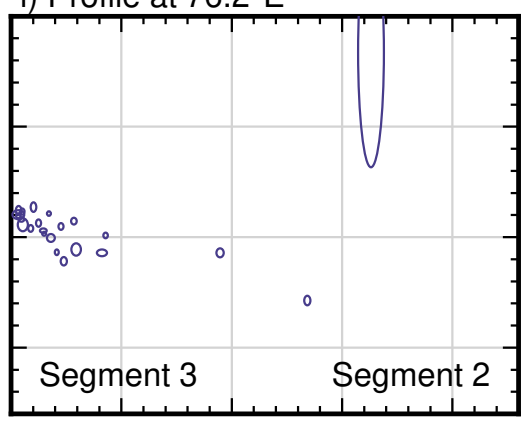

Figure S13. North-south seismicity profiles across segments 1 and 2, oblique to segment 3, ellipses indicating $95 \%$ location confidence. Profile width $0.2^{\circ}$. Seismicity located in $1-\mathrm{D}$ velocity model of Sippl, Schurr, Yuan, et al. (2013). 


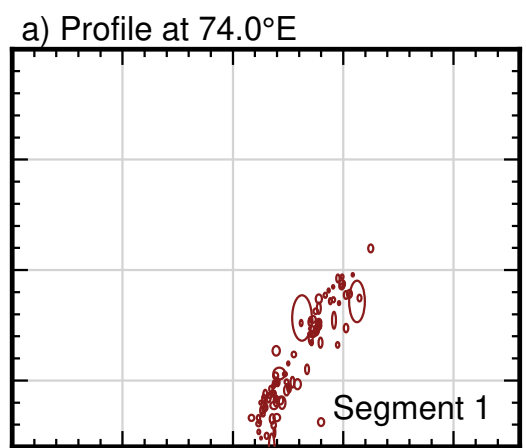

d) Profile at $74.6^{\circ} \mathrm{E}$

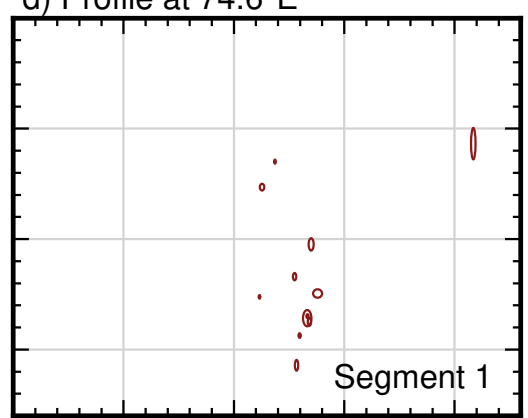

g) Profile at $75.2^{\circ} \mathrm{E}$
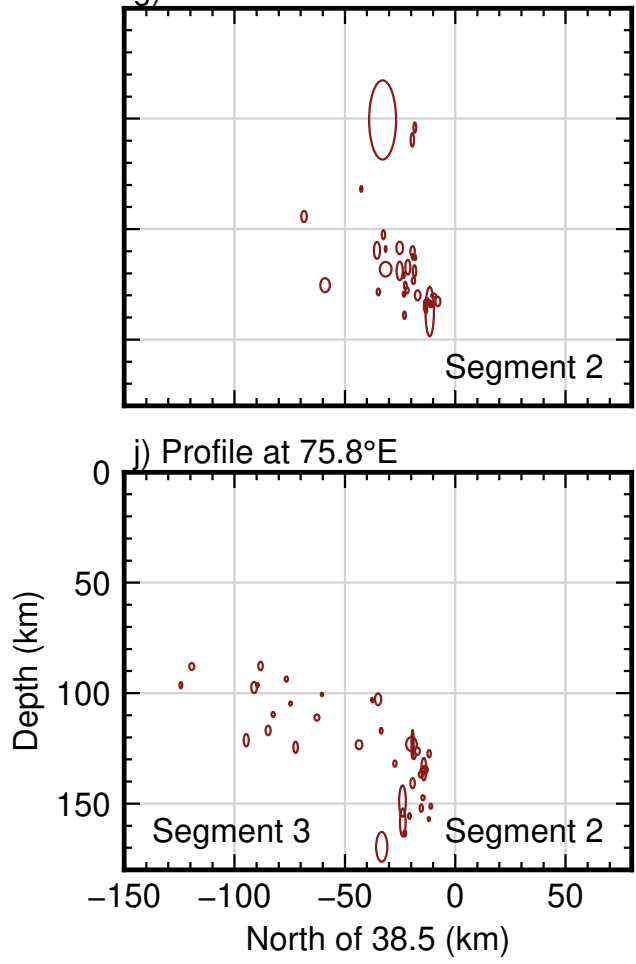

b) Profile at $74.2^{\circ} \mathrm{E}$

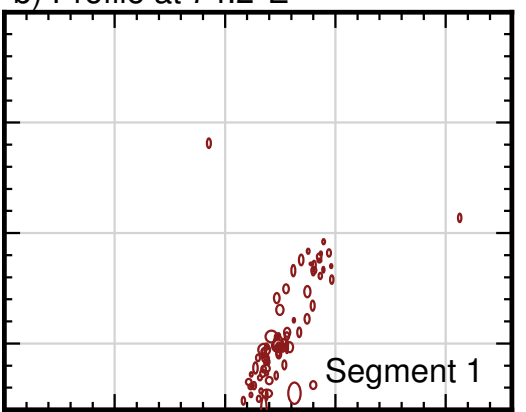

e) Profile at $74.8^{\circ} \mathrm{E}$

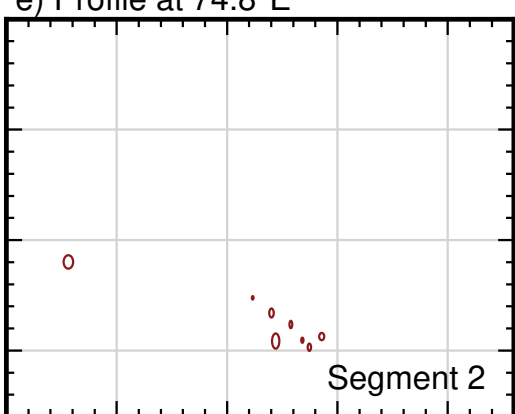

h) Profile at $75.4^{\circ} \mathrm{E}$

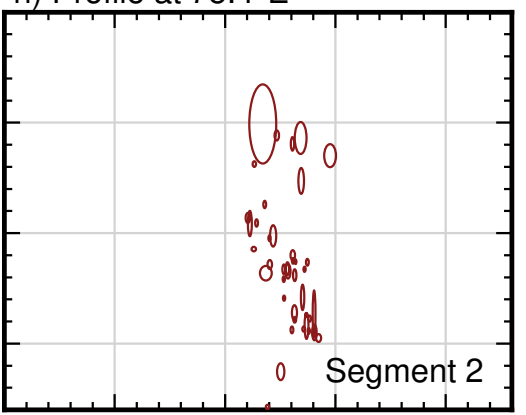

k) Profile at $76.0^{\circ} \mathrm{E}$

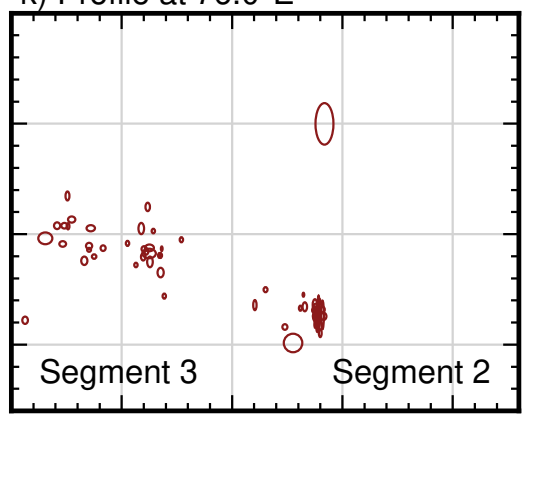

c) Profile at $74.4^{\circ} \mathrm{E}$

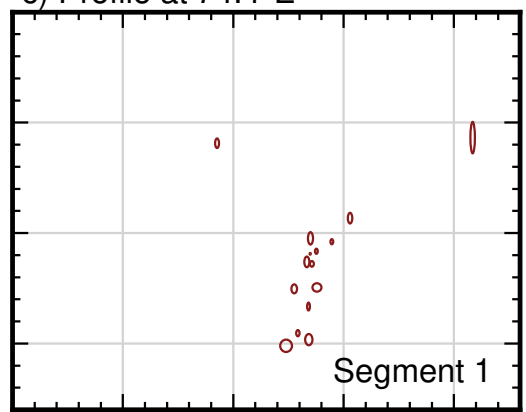

f) Profile at $75.0^{\circ} \mathrm{E}$

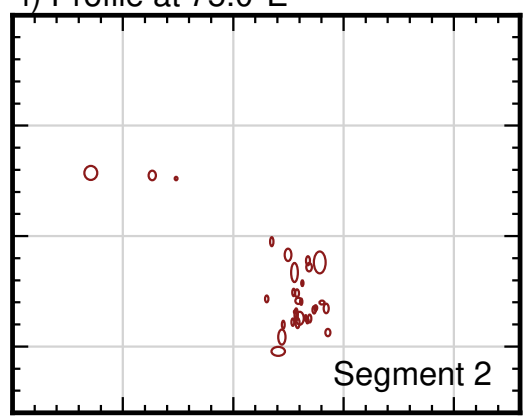

i) Profile at $75.6^{\circ} \mathrm{E}$

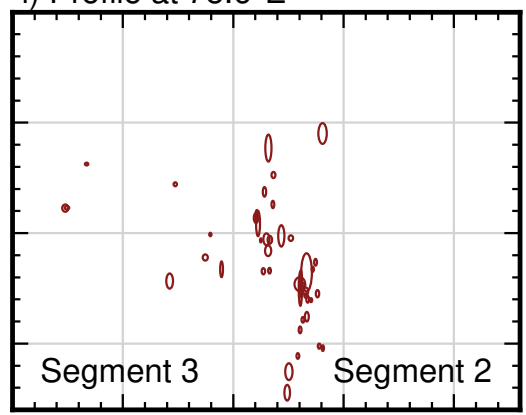

I) Profile at $76.2^{\circ} \mathrm{E}$

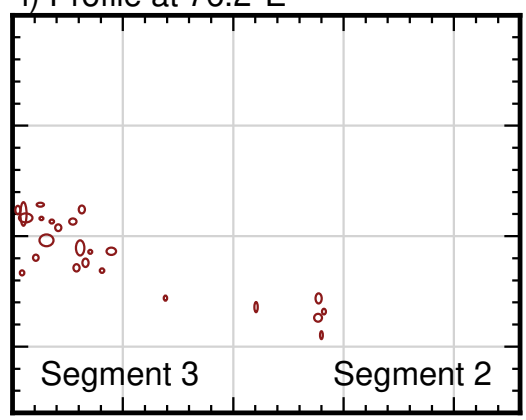

Figure S14. As Fig. S14, but only intermediate-depth seismicity $(>50 \mathrm{~km})$ relocated in the present 3-D velocity, and adjusted relative locations. 

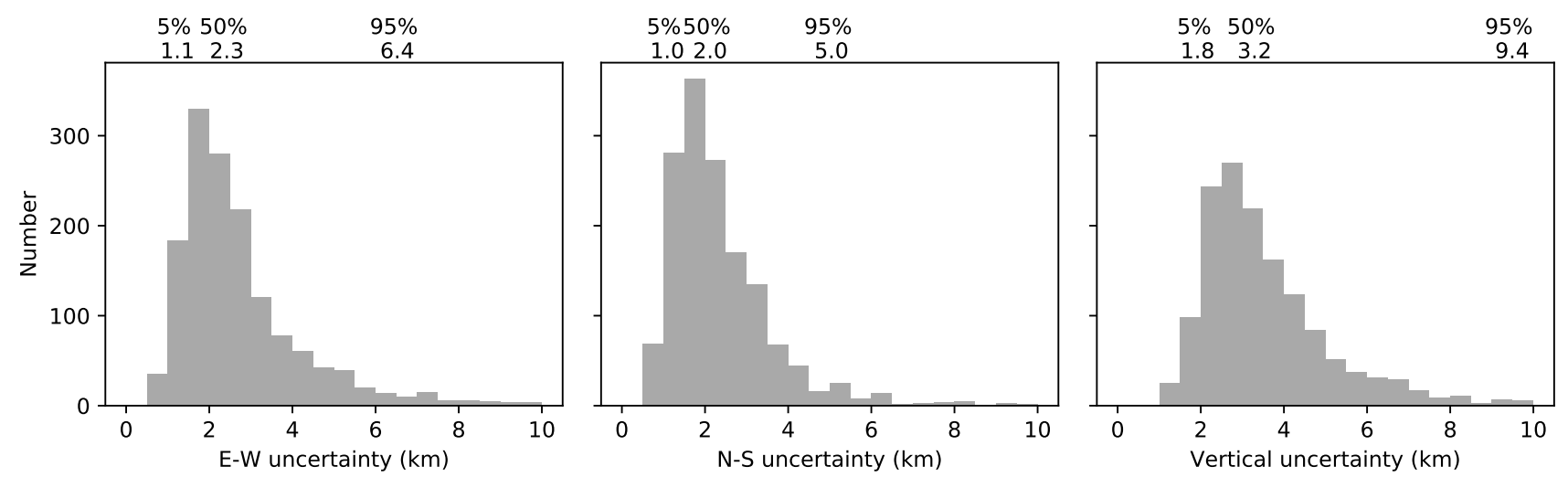

Figure S15. Location uncertainties of earthquakes at intermediate depth in east-west, northsouth and vertical direction. Top row indicates 5\%, 50\% (median), and 95\% quantiles.
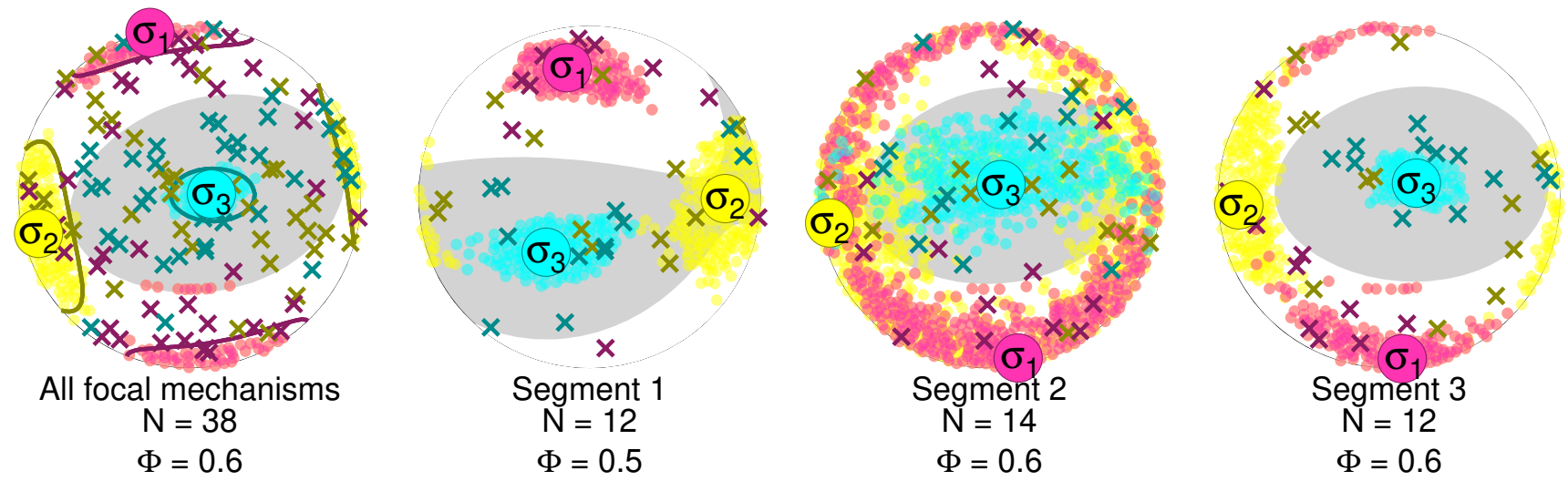

Figure S16. Results of stress tensor inversion for (left) all focal mechanisms, as in Fig. 2 of the main text, and (second left to right) clustered subsets of the respective segments. All lower hemisphere stereographic projections. Crosses mark input P- (magenta), N- (yellow), and T-axes (cyan). $\sigma_{1}, \sigma_{2}$, and $\sigma_{3}$ are largest, intermediate and smallest principal stress. Transparent dots mark the $95 \%$ confidence intervals determined by bootstrapping. Gray shaded background represents positive regions of the stress tenor, white negative. $\mathrm{N}$ : number of observations. $\Phi$ : shape factor $\frac{\sigma_{2}-\sigma_{1}}{\sigma_{3}-\sigma_{1}}$ 

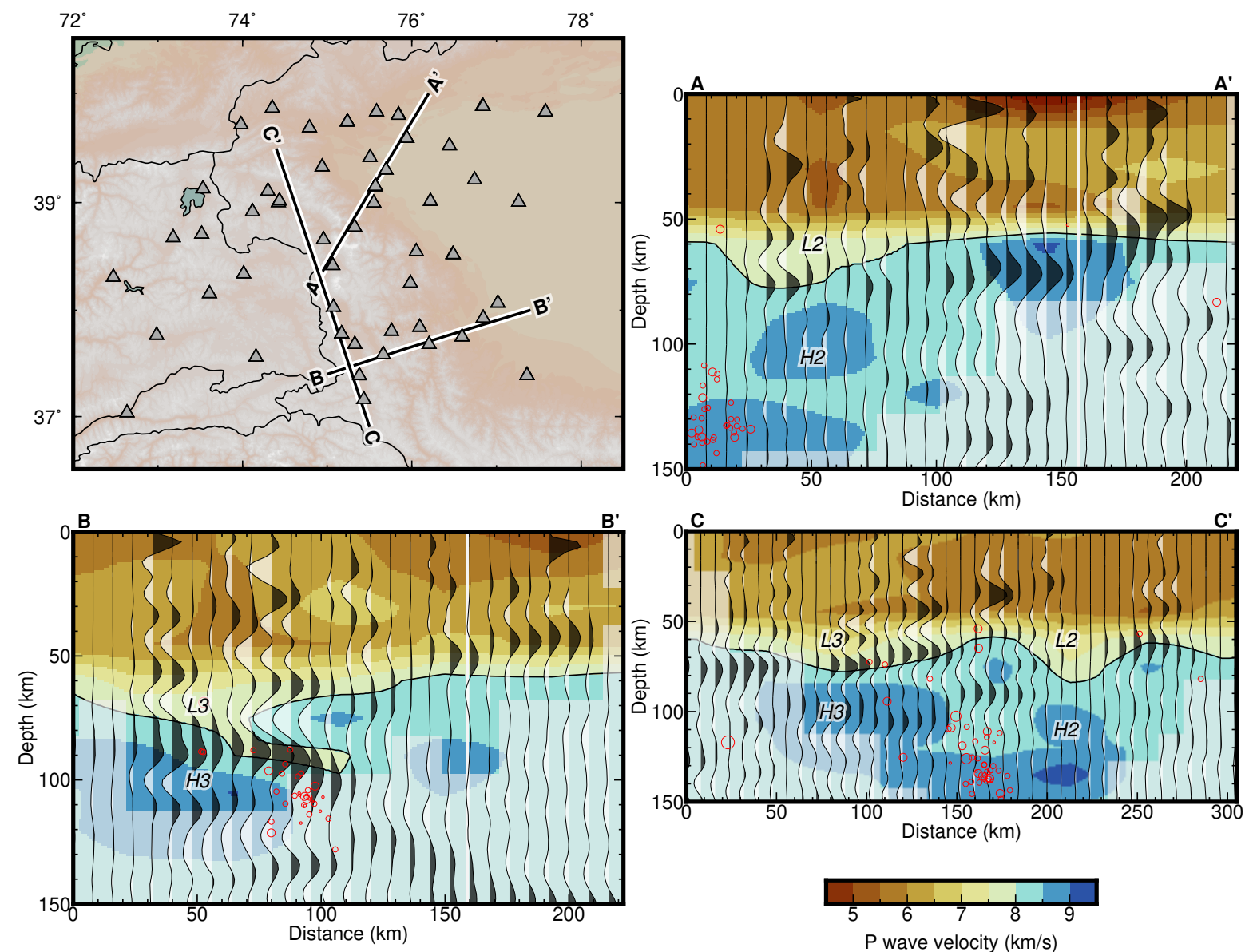

Figure S17. Profiles through the tomogram with common conversion point receiver function stacks along profiles of $\mathrm{Xu}$ et al. (2021) superimposed. Profile locations are guided by the station distribution and intersect the interpreted subsurface structures at oblique angles. The tomographic Moho $(8 \mathrm{~km} / \mathrm{s}$ contour) coincides in many places with the positive Moho conversion signal. The velocity contrasts L2/H2 and L3/H3 in the tomogram, that we interpret in the main article, show also a clear conversion signal. 